\title{
1 Electrospun materials as potential platforms for bone tissue engineering ${ }^{\text {is }}$
}

\author{
Jun-Hyeog Jang ${ }^{c}$, Oscar Castano ${ }^{\text {d,e }}$, Hae-Won Kim ${ }^{\text {a,b,e,* }}$ \\ a Department of Biomaterials Science, School of Dentistry, Dankook University, South Korea \\ b Biomaterials and Tissue Engineering Lab, Department of Nanobiomedical Science \& WCU Research Center, Dankook University, South Korea \\ c Department of Biochemistry, Inha University College of Medicine, South Korea \\ d Department of Material Sciences and Metallurgical Engineering, Institute of Bioengineering of Catalonia (IBEC), Universitat Politècnica de Catalunya, Barcelona, Spain \\ e Institute of Tissue Regeneration Engineering (ITREN), Dankook University, South Korea
}

\section{A R T I C L E I N F O}

\section{Article history:}

Received 8 December 2008

Accepted 16 July 2009

Available online $\mathrm{xxxx}$

\section{Keywords:}

Electrospun nanofiber

Bone tissue engineering

Biomimetic matrix

Bone bioactivity

3D scaffolding

\begin{abstract}
A B S T R A C T
Nanofibrous materials produced by electrospinning processes have attracted considerable interest in tissue 23 regeneration, including bone reconstruction. A range of novel materials and processing tools have been 24 developed to mimic the native bone extracellular matrix for potential applications as tissue engineering 25 scaffolds and ultimately to restore the degenerated functions of the bone. Degradable polymers, bioactive 26 inorganics and their nanocomposites/hybrids nanofibers with suitable mechanical properties and bone 27 bioactivity for osteoblasts and progenitor/stem cells have been produced. The surface functionalization with 28 apatite minerals and proteins/peptides as well as drug encapsulation within the nanofibers is a promising 29 strategy for achieving therapeutic functions with nanofibrous materials. Recent attempts to endow a 3D 30 scaffolding technique to the electrospinning regime have shown some promise for engineering 3D tissue 31 constructs. With the improvement in knowledge and techniques of bone-targeted nanofibrous matrices, 32 bone tissue engineering is expected to be realized in the near future.
\end{abstract}

(C) 2009 Published by Elsevier B.V. 34

\section{Contents}

1. Introduction

2. Bone and tissue engineering

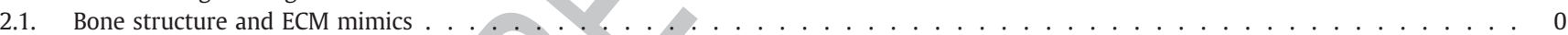

2.1.1. Bone structure: bone cells, ECMs and organization . . . . . . . . . . . . . . . . . . . . . . . 0

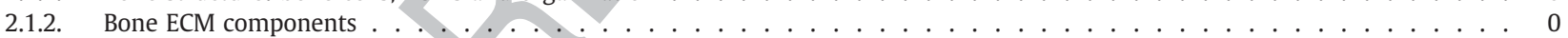

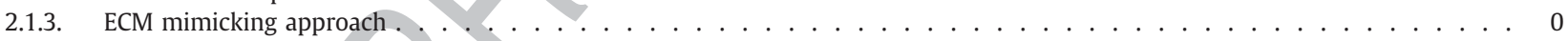

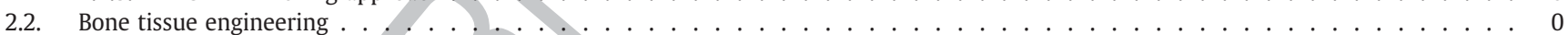

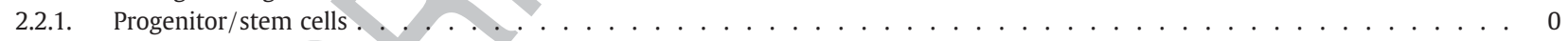

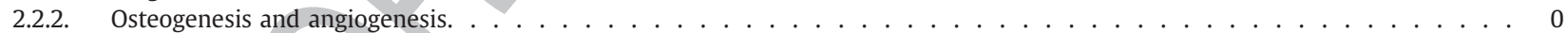

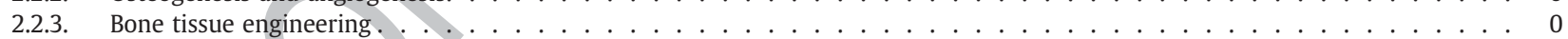

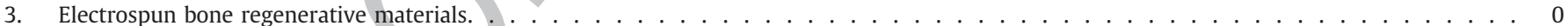

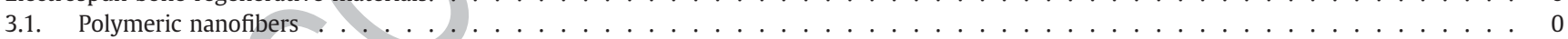

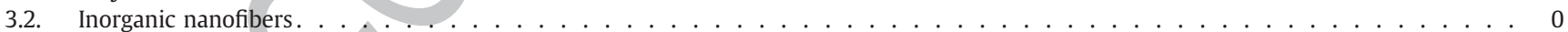

3.3. Polymer-inorganic composite hybridized nanofibers. . . . . . . . . . . . . . . . . . . . . . . . . . . . . . . . 0

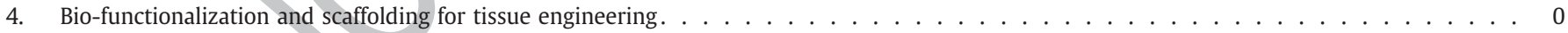

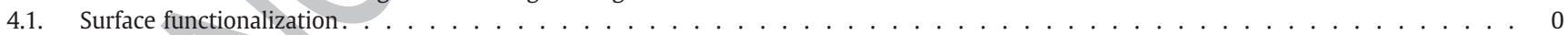

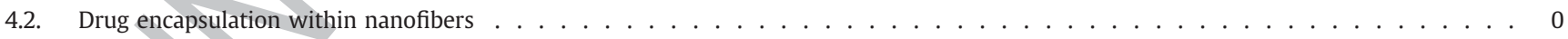

4.3. Scaffolding for cell growth and tissue engineering. . . . . . . . . . . . . . . . . . . . . . . . . . . . . . 0

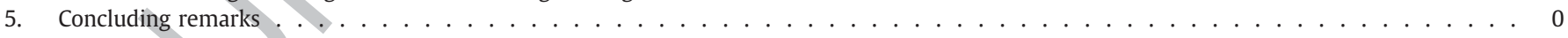

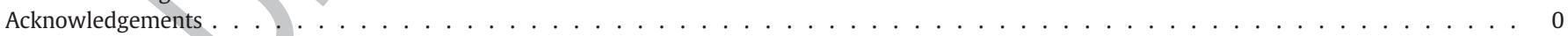

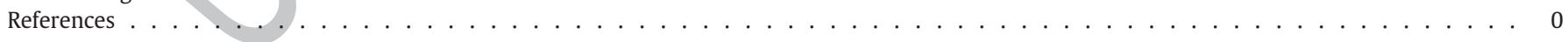

is This review is part of the Advanced Drug Delivery Reviews theme issue on "Nanofibers in Regenerative Medicine \& Drug Delivery".

* Corresponding author. Department of Biomaterials Science, School of Dentistry, Dankook University, Shinbu, Cheonan, $330-714$, South Korea. Tel./fax: +82 41 550 1926. E-mail address: kimhw@dku.edu (H.-W. Kim). 


\section{Introduction}

The treatment of bone defect sites with medical-grade materials is widely performed with some degree of clinical success. The manipulation of biomaterials in concert with tissue cells is considered a promising and alternative therapy to the autologous surgery [1]. This tissue engineering approach to bone reconstruction, having gained significant interest and research input over the last decade, requires a suitable cell supporting matrix, namely a scaffold, to provide a 3dimensional substrate for cells to populate on and function appropriately during the formation of bone analog tissue [2,3].

There have been significant advances in the development of bone scaffolds with various compositions and 3-dimensional configurations using a variety of techniques $[4,5]$. Recently, the electrospinning process and the nanofibrous matrices thus fabricated have gained tremendous interest, mainly due to the structural similarity to the tissue extracellular matrix (ECM), the processing availability to a wide range of materials, as well as simple set-up and operation at low cost [6-10]. Several studies have reported the performance of nanofibrous materials in guiding cells to initially adhere to and spread over the material, as well as further triggering them to secrete the appropriate ECM molecules targeted to the skin, blood vessel, cartilage, muscle, adipose, nerve and bone. The intriguing features of a fibrous morphology with diameters ranging from tens of nanometers to a few micrometers have attracted considerable attention focused on exploiting the properties as well as structural tuning to the tissue of concern for the applications as a tissue engineering scaffold.

In the bone reconstruction area, the electrospun nanofibers have also attracted considerable attention from scientists aimed at identifying suitable material compositions and exploiting them into electrospinning [11,12]. As the bone-associated cells and their progenitor/stem cells show initial responses in a similar manner to those in other tissue cells, which are anchorage-dependent, the nanofibrous substratum may provide favorable conditions for cell anchorage and growth. In tandem with the initial cell responses, further osteoblastic differentiation and mineralization have also been reported to be regulated in a positive manner on nanofibrous surfaces compared to a dense substrate of polymers [13].

Although studies on the in vivo feasibility of electrospun nanofibers in bone reconstruction and tissue engineering progress are currently in the early stages, recent reports of electrospun nanofibers with new compositions targeted for bone as well as some processing tools to design 3-dimensional scaffolding and tissue engineering have highlighted the potential use of electrospun materials in bone tissue engineering.

This review consists of three parts: a brief introduction of the bone structure, which is to be mimicked by electrospun nanofibrous matrices, and the bone tissue engineering concept; a research summary of electrospun materials targeted for bone regeneration, including polymers, inorganics and their composites/hybridized compositions; and a description of on-going efforts aimed at employing nanofibrous matrices for drug delivery and tissue engineering, which was facilitated by surface functionalization, drug encapsulation and 3D scaffolding technique.

\section{Bone and tissue engineering}

\subsection{Bone structure and ECM mimics}

\subsubsection{Bone structure: bone cells, ECMs and organization}

It is important to understand the biomechanical and biological properties of bone in order to gain insight into choosing the type of materials that can best be used to reconstruct the degenerative functions of bone. Bone is a complex, highly organized and specialized connective tissue. Compared to soft tissues, bone is physically hard, rigid and strong, and microscopically contains relatively few cells with abundant intercellular matrix in the form of collageneous fibers and stiffening inorganic substances. There are three types of cells comprising bone as illustrated in Fig. 1.

Osteoblasts located on the surfaces of bone are responsible for the formation and organization of the extracellular matrix of bone and its subsequent mineralization. These cells are responsible for the synthesis of organic components of the bone ECM. They are derived from mesenchymal precursor cells in the marrow, which also has the potential to differentiate into fat cells, chondrocytes or muscle cells [14]. The principal products of mature osteoblast are type I collagen ( $90 \%$ of the protein in bone), bone specific vitamin-K dependent proteins, osteocalcin and matrix Gla protein, phosphorylated glycoproteins including bone sialoproteins I and II, osteopontin and osteonectin, proteoglycans and alkaline phosphatase.

A proportion of osteoblasts become trapped as osteocytes in the lacunae within the bone matrix. These cells may be responsible for intercellular communication. They possess long thin cytoplasmic processes called filopodia located in thin cylindrical spaces or canals in the bone matrix. Nutrients and oxygen pass between the blood vessels and distant osteocytes via the arrangement of the canaliculi. Osteocytes also break down the bone matrix through osteocytic osteolysis to release calcium for calcium homeostasis [15].

Osteoclasts are polarized cells with a ruffled border region of the cell membrane that is surrounded by an organelle-free region, or "clear zone'. They adhere to the bone surface via integrins, which are specialized cell surface receptors [16]. Osteoclastic bone resorption initially involves mineral dissolution, followed by degradation of the organic phase. These processes take place beneath the ruffled border and depend on lysosomal enzyme secretion and an acid microenvironment [17]. Osteoclasts actively synthesize lysosomal enzymes, particularly the tartrate-resistant isoenzyme of acid phosphatase (TRAP) (used as a marker of the osteoclast phenotype), and cysteine-proteinases, such as cathepsins, which are capable of degrading collagen. Lysosomal enzymes are released only at the ruffled border region of the osteoclast cell membrane [18].

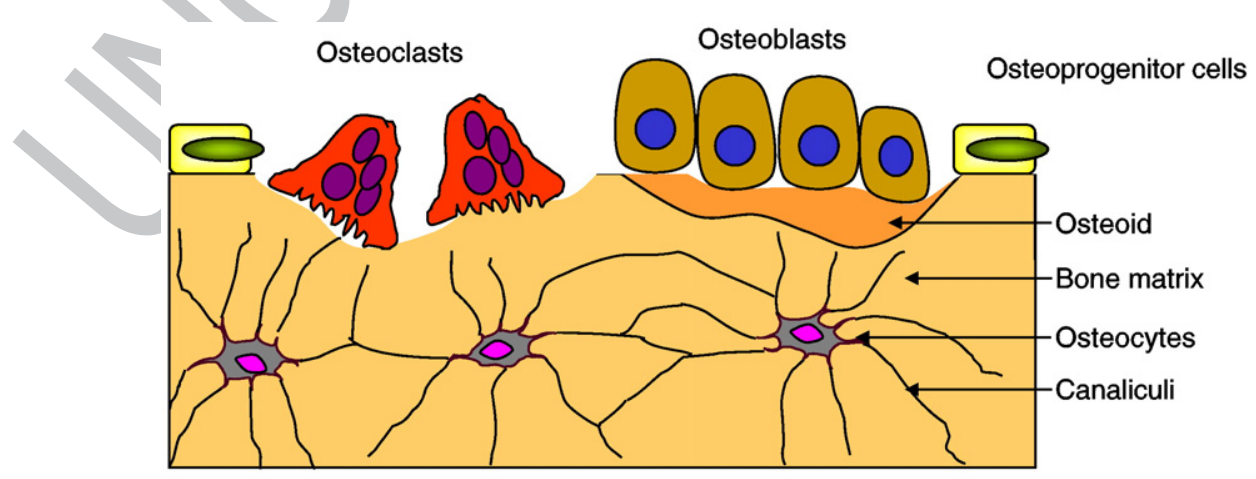

Fig. 1. Schematic diagram of bone structure at cellular level. 


\subsubsection{Bone ECM components}

Type I collagen is a major organic component of mineralized ECM, comprising $90-95 \%$ of the organic material and serves as a template upon which mineral is deposited. Type $\mathrm{V}$ collagen is also present in small quantity, as are a number of non-collageneous proteins, some of which are relatively specific to bone [19].

In addition to the major collagen matrix, bone contains several other non-collageneous proteins. Osteocalcin is a $6-\mathrm{kDa}$ noncollageneous protein and comprises up to $15 \%$ of the noncollageneous protein of the mature bone [20]. The osteocalcin expression is largely restricted to the osteoblasts of bone as well as the odontoblasts and cementoblasts of teeth [21]. The structure of osteocalcin is characterized by three glutamic acid residues that undergo vitamin K-dependent carboxylation. The $\gamma$-carboxyglutamic acid residues (Gla) provide osteocalcin with the ability to bind bone mineral hydroxyapatite with high affinity [22]. Osteocalcin is the second most abundant protein in the bone matrix, and it is highly conserved in all vertebrate species [23]. The biological function of osteocalcin is probably related to the regulation of bone turnover and/or mineralization [24].

Osteopontin is a secreted, glycosylated phosphoprotein that is found normally in mineralized tissues, such as bones and teeth, in addition to the kidneys, urine and epithelial lining cells in numerous organs [25]. Osteopontin supports cell adhesion through its Arg-GlyAsp (RGD) integrin recognition motif. Osteopontin is also rich in aspartic acid residues and can be heavily glycosylated. The acidic nature of osteopontin probably accounts for its ability to modulate the growth of calcium crystals in both bone [26] and urine [27]. Osteopontin is a multifunctional protein that promotes cell adhesion and migration, inhibits bone mineral formation, and binds $\mathrm{Ca}^{2+}$ $[28,29]$ Osteopontin can exist in a variety of forms depending on the extent of post-translational modification. A highly phosphorylated form of osteopontin can be isolated from the mineralized extracellular matrix of bone tissue, and is synthesized by osteoblasts [30].

The ECM plays an important role in the function of growth factors [31]. This cooperative/synergistic process may involve the convergence of intracellular signaling pathways triggered by the ECM proteins and growth factors, and becomes important in the tissue regeneration process. In addition to its serving as a scaffolding for mineralization, the ECM proteins function as a substratum for bone cell adhesion and differentiation. Once engaged with the matrix, the bone cells sense deformation and other changes within the bone (matrix-cell crosstalk) [32]. On the other hand, they may interact with their surroundings by anchoring and pulling on the matrix, as has been shown for other cell types (cell-matrix crosstalk) [33]. The summary of the bone ECM proteins is shown in Table 1.

\subsubsection{ECM mimicking approach}

Given that defective bone can recover with the use of artificial materials, bone-associated cells should be directed to recognize and respond appropriately to form bone ECM that is analogous to the native bone matrix. Therefore, it is favored to design and engineer materials with structure, composition and properties similar to the

Table 1

The ECM proteins found in bone.

\begin{tabular}{|c|c|c|c|}
\hline \multicolumn{2}{|l|}{ ECM proteins } & \multirow{2}{*}{$\begin{array}{l}\text { Function } \\
\text { Tensile strength }\end{array}$} & Comments \\
\hline Collagens & Collagen type I & & $90 \%$ of total \\
\hline & Collagen type V & Tensile strength & bone protein \\
\hline \multirow[t]{6}{*}{ Noncollagen proteins } & $\begin{array}{l}\text { Osteocalcin } \\
\text { (bone Gla protein) }\end{array}$ & Mineralization & \\
\hline & Osteopontin & $\begin{array}{l}\text { Cell adhesion, } \\
\text { Mineralization }\end{array}$ & Bone sialoprotein-1 \\
\hline & Bone sialoprotein-2 & Mineralization & \\
\hline & Osteonectin (SPARC) & Cell adhesion & \\
\hline & Fibronectin & Cell adhesion & \\
\hline & Thrombospondin & Cell adhesion & \\
\hline
\end{tabular}

bone ECM [34]. Bone mimicking materials should play active roles in assisting cells to follow processes that are effective in bone formation. The major organic bone matrix consists of collageneous fibrils interwoven within hydrated polysaccharide chains, acting efficiently in response to external stress, and transmitting signals to the cell membrane receptors that reach the nucleus via intracellular signaling cascades. More importantly, within the organic network, inorganic nanocrystallites (mostly hydroxyapatite phase) are mutually incorporated. Therefore, the bone ECM is a type of organic-inorganic nanocomposite, organized on the nanoscale, in which bone is allowed to perform good biomechanical functions and biological roles [35]. Besides collageneous fibers and inorganic mineral nanocomponents, a variety of key proteins and growth factors are present in the bone matrix and are involved in bone formation, and should also be considered in the design of ECM mimicking materials. Overall, a nanofibrous matrix that can be produced by electrospinning is believed to be able to retain bone ECM components and be engineered to modulate the microenvironments further to form tissue mimics in the course of ex vivo tissue engineering or under in vivo situations [36]. This drives us to focus on a tissue engineering approach where the native bone structure can be better mimicked because bone actually contains both ECM and cell components.

\subsection{Bone tissue engineering}

\subsubsection{Progenitor/stem cells}

The recent emerging strategy in bone tissue engineering is to use stem cells. Many adult tissues contain populations of stem cells that have the capacity for renewal. These cells may be found within the tissue or in other tissues that serve as stem cell reservoirs. For example, although bone marrow is a major source of adult hematopoietic stem cells (HSCs) that renew circulating blood elements, these cells can also be found in other tissues [37]. Adult bone marrow also contains mesenchymal stem cells (MSCs), which contribute to the regeneration of mesenchymal tissues, such as bone, cartilage, muscle, ligament, tendon, adipose, and stroma [38]. Therefore, they are an attractive cellular source for bone tissue engineering applications. Under permissive stimulation, MSCs undergo osteogenic differentiation through a well-defined pathway, acquiring osteoblastic markers and secreting extracellular matrix and calcium crystals [39]. In vitro and animal implantation studies have suggested that the population is either multipotent MSCs or mixtures of committed progenitor cells, each with a restricted potential [40]. However, clinical translation is impeded by the low population of MSCs in bone marrow, particularly in older age groups in whom fractures and non-union are common.

Blood mesenchymal precursor cells (BMPCs) have been a central focus in regenerative medicine for bone regeneration ever since these cells were first found to exist in the circulation of healthy patients. BMPCs were discovered by Zvaifler et al., who reported that these cells adhere to plastic and glass and proliferate logarithmically in DMEM$20 \%$ fetal calf serum without growth factors, which suggests that these cells are relatively easy to expand in vitro [41]. After adding osteogenic supplements (e.g., dexamethasone, ascorbic acid, and beta-glycerophosphate) into the culture, fibroblast formation is inhibited, and the BMPCs then assume the more cuboidal shape of osteoblasts, as confirmed by alkaline phosphatase (ALP) and osteocalcin staining. This group further demonstrated that circulating osteocalcin positive cells also deposit minerals in vitro and bone in vivo in immunodeficient mice [42]. They also reported that circulating osteocalcin positive cells are predominantly small, round cells that are phenotypically similar to the cells originally isolated from the nonadherent bone marrow population by Long et al. [43]. Given the osteogenic potential of circulating blood mesenchymal cells, exposing these cells to osteogenic factors is a potent stimulus for bone formation. Otsuru et al. recently reported that osteoblast progenitor cells in the circulation that originate from the blood mesenchyme form ectopic 
t 2.15

t2.16 bone after being implanted with a bone morphogenetic protein (BMP)-2-containing collagen pellet into skeletal muscle beds of mice [44].When these pellets were implanted into GFP transgenic mice, there was a significant number of GFP-positive osteoblastic cells engrafting into the ectopic bone after circulatory migration to the osteogenic site.

More recently, MSCs with osteogenic potential have been isolated from a wide variety of tissue types, including adipose tissue, umbilical cord blood, amniotic fluid and fetal blood [45,46]. However, it is unclear how these novel fetal perinatal and adult MSC sources compare with their standard adult blood MSC counterparts for osteogenic differentiation and potential for bone tissue engineering.

\subsubsection{Osteogenesis and angiogenesis}

The development of osteogenesis occurs through two distinct processes: intramembranous and endochondral ossification. In intramembranous ossification, bone is formed by the differentiation of mesenchymal cells into osteoblasts in the absence of a cartilaginous model. The flat bones of the skull, sternum, and scapula are examples of bones that develop through intramembranous ossification. The term endochondral refers to the close association of the developing bone with the pre-existing hyaline cartilage model of that bone. The long bones of the limbs (including the phalanges) and ribs develop through endochondral ossification.

Recently, studies using in vitro and in vivo models of osteogenesis highlighted the importance of blood vessels in the formation of the skeleton and bone repair [47]. The vasculature transports oxygen, nutrients, soluble factors and numerous cell types to the bone tissues. There are a number of factors involved in angiogenesis, and the main factors are Vascular Endothelial Growth Factor (VEGF), Fibroblast Growth Factor-2 (FGF-2), and various members of the Transforming Growth Factor beta (TGF- $\beta$ ) family [48]. Recent studies have shown that a combination of angiogenic and osteogenic factors can stimulate bone repair and regeneration [49]. Therefore, the delivery a combined system of growth factors at different rates locally from an engineered biodegradable nanofibrous scaffold might enhance the reparative mechanism of critical sized bone defects, thereby mimicking the in vivo bone repair conditions. The multiple release of growth factors, such as VEGF and BMP, may mimic the conditions in bone fracture repair. Hence, scaffolds capable of releasing an active angiogenic factor will promote early vascularization and attract osteogenic precursor cells. Huang et al. reported that PLGA scaffolds containing a combination of plasmids encoding DNA for BMP-4, VEGF and human bone marrow stromal cells promoted greater bone formation when implanted into the subcutaneous tissue of SCID mice than those containing a single factor or a combination of two factors [50].

\subsubsection{Bone tissue engineering}

Bone tissue engineering has become a rapidly expanding research area because it offers a new and promising approach for bone repair and regeneration [51]. Typically, bone tissue engineering approaches involve the use of scaffolding materials in combination with tissue

Table 2

Summary of electrospun nanofiber systems produced for the bone reconstruction.

\begin{tabular}{|c|c|c|c|c|c|}
\hline Composition & & Fiber diameter & Assays & Remarks & Ref. \\
\hline \multirow[t]{3}{*}{ Synthetic polymers } & PLA ( $L$ - and $D L$-type) & $141-2140 \mathrm{~nm}$ & MC3T3-E1 & Effect of osteogenic factors and fiber size & {$[55]$} \\
\hline & PCL & $20-5000 \mathrm{~nm}$ & BMSC, in vivo (rat) & Tissue engineering & {$[11,54]$} \\
\hline & PHB, PHBV, blend & $2000-4300 \mathrm{~nm}$ & SaOS-2 \& L929 & & [56] \\
\hline \multirow[t]{4}{*}{ Natural polymers } & Collagen I & $50-1000 \mathrm{~nm}$ & hMSC & & [63] \\
\hline & Chitosan & $200 \mathrm{~nm}$ & MG63, in vivo (rabbit) & Bone formation at 4 weeks & [69] \\
\hline & Silk fibroin & $217-610 / 183-810 \mathrm{~nm}$ & MC3T3-E1 & & [66] \\
\hline & Silk fibroin & $700 \mathrm{~nm}$ & BMSC & Poly(ethylene oxide) (PEO) addition & [65] \\
\hline \multirow[t]{3}{*}{ Polymer blends } & PCL-gelatin & tens of nm-1000 nm & BMSC & Cell penetration with gelatine addition & [57] \\
\hline & PLLA-gelatin & $190-390 \mathrm{~nm}$ & МС3Т3-E1 & Enhanced cell responses on blends & [58] \\
\hline & PCL-heparan sulfate & - & BMSC & Osteogenic differentiation & [59] \\
\hline \multirow[t]{6}{*}{ Inorganics } & Bioactive glass & $84-630 \mathrm{~nm}$ & Production, bone bioactivity, rBMSC & Excellent bone bioactivity and BMSC responses & [70] \\
\hline & Bioactive glass & $320 \mathrm{~nm}$ & Production, osteoblast adhesion & FN-introduction, enhanced cell adhesion & [75] \\
\hline & $\begin{array}{l}\text { Hydroxyapatite and } \\
\text { fluoro-hydroxyapatite }\end{array}$ & $240-1550 \mathrm{~nm}$ & Production, dissolution & Reduced dissolution by fluorine addition & [71] \\
\hline & Hydroxyapatite & $10-30 \mathrm{~mm}$ & Production & Microfibers & [72] \\
\hline & Hydroxyapatite & $200-500 \mathrm{~nm}$ & Processing & & [73] \\
\hline & Silicate & - & In vitro (MG63) & Apatite forming ability & [74] \\
\hline \multirow{8}{*}{ Composites/hybrids } & Gelatin-hydroxyapatite & $200-400 \mathrm{~nm}$ & Production, osteoblasts & Enhanced osteoblastic differentiation & [79] \\
\hline & Collagen-hydroxyapatite & $75-160 \mathrm{~nm}$ & Production, osteoblasts & & [80] \\
\hline & Chitosan-hydroxyapatite & $\sim 214 \mathrm{~nm}$ & hFOB & PEO addition & [81] \\
\hline & $\mathrm{PCL}-\mathrm{CaCO}_{3}$ & $\sim 760 \mathrm{~nm}$ & Mechanical test, in vitro (hFOB) & GBR membrane application & [82] \\
\hline & PLLA-hydroxyapatite & $\sim 1000-2000 \mathrm{~nm}$ & Production, MG63 & Surfactant introduction & [83] \\
\hline & Siloxane-gelatin & 40 to $670 \mathrm{~nm}$ & Production, MC3T3-E1 & Hybridized structure, Ca requirement & [84] \\
\hline & PCL-HA-collagen & $\sim 370 \mathrm{~nm}$ & hFOB & & [85] \\
\hline & PCL- $\beta T C P$ & $200-2000 \mathrm{~nm}$ & Osteoblast responses & Better cell adhesion due to $\beta$ TCP & [86] \\
\hline \multirow[t]{5}{*}{ Surface functionalized } & PCL & $\sim 250 \mathrm{~nm}$ & $\begin{array}{l}\text { Production, osteoblasts, PDL } \\
\text { fibroblasts }\end{array}$ & $\begin{array}{l}\text { Apatite mineralized, higher osteogenic } \\
\text { responses }\end{array}$ & $\begin{array}{l}{[87]} \\
{[88]}\end{array}$ \\
\hline & PLLA & $200-2200 \mathrm{~nm}$ & Production & $\mathrm{NaOH}$-treatment & [89] \\
\hline & PDLLA & - & Production & $\mathrm{Ca}\left(\mathrm{NO}_{3}\right)_{2}$ addition & [90] \\
\hline & PLLA, PLLA-collagen & $287-364 \mathrm{~nm}$ & hFOB & Mineralization with collagen & [91] \\
\hline & PLGA, PLGA-PEG & $-{ }^{\lambda}$ & Fibroblast adhesion & Amination, RGD-immobilization & [94] \\
\hline \multirow[t]{4}{*}{ Drug/gene delivery } & PLA, PCL & - & Antibacterial effects & Antibiotic delivery & [96] \\
\hline & & & & & [97] \\
\hline & $\begin{array}{l}\text { Silk, Silk-PEO } \\
\text { (+ hydroxyapatite) }\end{array}$ & $510-590 \mathrm{~nm}$ & hMSC responses & BMP2 efficacy on osteogenesis & [98] \\
\hline & PLGA-HA & $250-875 \mathrm{~nm}$ & In vitro gene transfection & BMP encapsulation in chitosan nanoparticles & {$[101]$} \\
\hline
\end{tabular}

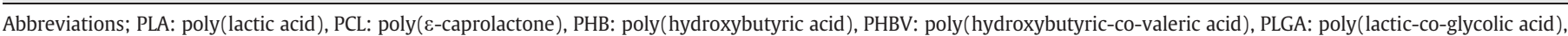

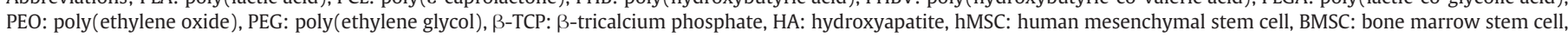
hFOB: human fetal osteoblast. 
cells and biological cues. An advanced scaffolding material for tissue engineering must exhibit high quality, reliability, sustainability and cost-effectiveness throughout the individual's life and provide new advanced levels of medical assistance in therapy and surgery. One particular requirement of bone tissue engineering is that the scaffold be porous because large numbers of cells can be incorporated in that form. The three dimensional scaffolds provide the necessary support for cells to attach, grow and differentiate, and define the overall shape of a bone tissue engineered transplant [1]. A range of biomaterials have been investigated for use in bone tissue engineering scaffolds, which can be classified mainly into three categories according to the composition: bioactive inorganics, degradable polymers and their composites/hybridized forms [52]. Gigante et al. evaluated the behavior of human MSCs cultured on various scaffolds to determine if their differentiation can be induced by cell-matrix interactions [53]. They reported that MSCs grown on type I + II collagen differentiated to cells expressing chondrocyte markers, while those grown on type I collagen + hydroxyapatite differentiated into osteoblast-like cells. Their study highlighted that human MSCs grown on different scaffold matrices can display different behaviors in terms of cell proliferation and phenotype expression [53].

Recent technological advances has facilitated the generation of a variety of scaffolds with a modulated pore configuration and nanostructure. Electrospun nanofibers are one of these recently highlighted systems that may find applications as a scaffolding material in bone tissue-engineered constructs.

\section{Electrospun bone regenerative materials}

Designing matrices suitable for the recruitment of osteoprogenitor/stem cells has been promoted by the approach of mimicking the composition, morphological traits and mechanical function of the native bone ECM. The beneficial features of a nanofibrous structure by electrospinning were first realized with degradable polymers, which stimulate cells into osteogenic pathway assisted via well-controlled differentiation cues.

However, a major part of the bone ECM also contains calcium phosphates mineral phases, which requires a mineralization step that is essential in the bone regeneration process. The existence of bonebioactive inorganic components within biomaterials generally favors calcium phosphate mineralization followed by an osteogenic differentiation process. Therefore, recent studies have focused on introducing a range of inorganic phases within the polymeric nanofibers with the ultimate aim of achieving both bone-specific bioactivity and mechanical properties.

A new strategy to designing nanofibers involves endowing biofunctionality onto the surface of nanofibers because the cells first recognize the surface of the material, which mostly regulates their responses. Modulation of a polymeric surface with materials that are more friendly and active to bone cells, such as a bone mineral-like phase, is one example of surface tailoring methods targeted for bone regeneration. Moreover, nanofibers that are surface-conjugated or incorporated internally with proteins and genes are an elegant way of utilizing nanofibrous matrices in drug delivery systems. In vitro data have demonstrated the potential of introducing cell adhesive proteins or peptides as well as osteogenic stimulatory signals including growth factors and genes. In Table 2, the electrospun nanofiber systems produced for the reconstruction of bone tissue are summarized.

Because of the inherent processing nature of electrospinning, which contains pores with sizes at best a few micrometers, the introduction of larger sized pores within the nanofibrous network are needed in order to identify extended and potential uses of bone tissue engineering 3D scaffolds. A few recent trials carried out to generate macro-sized pores and engineer 3D tissue constructs provided some insights into future work on bone tissue engineering using electrospun nanofibers as a scaffold.

\subsection{Polymeric nanofibers}

The electrospinning of degradable polymers, either with a synthetic or natural origin, was first reported to generate suitable bone cell matrices largely due to their ease of processing including solution preparation. Furthermore, the flexibility and shape-availability of polymeric materials gives them great potential in the bone regeneration area.

Among all polymeric materials, a group of poly ( $\alpha$-hydroxyl acid), such as poly(lactic acid) (PLA), poly(glycolic acid) (PGA), poly( $\varepsilon-$ caprolactone) (PCL) and their copolymers, has been the most extensively studied nanofiber system for the regeneration of tissues, including bone [3]. PCL was first suggested to be a degradable nanofiber matrix for the bone regeneration [11], which demonstrated good support of the rat bone marrow stromal cells (rBMSCs) and in vitro matrix formation at 4 weeks, such as collagen I and calcium phosphate mineral. Moreover, a cell-nanofiber construct implanted in
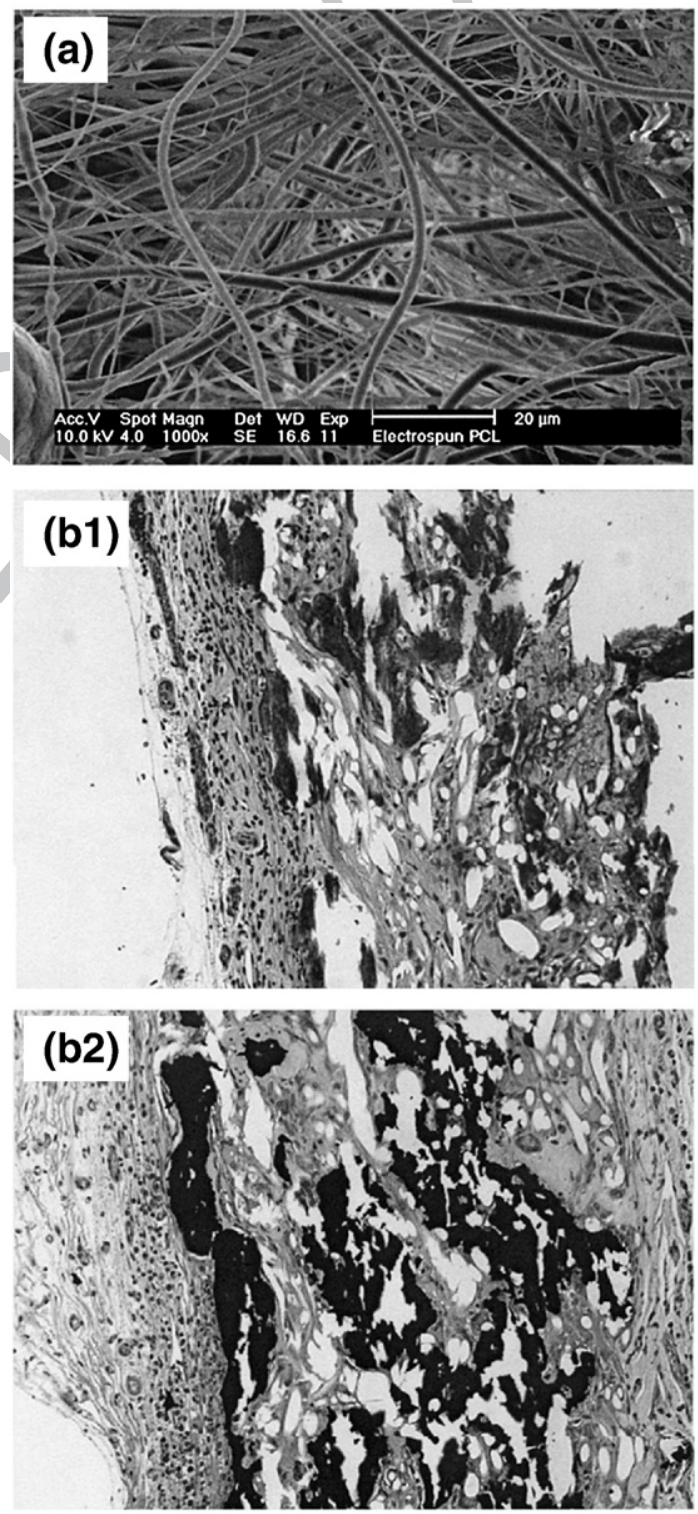

Fig. 2. (a) PCL electrospun nanofiber. (b1,b2) Histology cross-section of the explanted specimens after 4 weeks of in vitro culture and 4 weeks of implantation in the omentum of rat. (b1) Osteocyte-like cells embedded in bone matrix are present (H\&E; original magnification, $\times 3100)$. (b2) Mineralization has occurred throughout the specimen (von Kossa; original magnification, $\times 3100$ ). Adapted with permission from [54] copyright 2004 Mary Ann Liebert. 
rat omenta for 4 weeks revealed the formation of collagen I and mineralization similar to bone-like ECM, highlighting its usefulness in bone tissue engineering (Fig. 2) [54]. The PLA electrospun nanofibers with variable sizes were observed to affect the MC3T3-E1 cell responses [55]. Interestingly, when an osteogenic medium was used, a higher cell density was observed on the PLA nanofibers than on flat PLA. On the other hand, there was little difference observed when no osteogenic medium was used, suggesting the possible influence of osteogenic factors on the osteoblastic responses to the nanofibrous topology. Poly(hydroxyalkenoate)s, another class of degradable polyester polymer, was also developed into electrospun nanofibers for bone regeneration [56]. Poly(hydroxybutyrate) (PHB) and poly(hydroxybutyrate-co-hydroxyvalerate) (PHBV) nanofibers with relatively large diameters (approximately 2 to $4 \mu \mathrm{m}$ on average) exhibited better cell growth behavior (SaOS-2 cell line) than their equivalent flat film counterparts, and maintained the osteoblastic phenotype [56].

However, due to the innate hydrophobic nature, the initial cell adhesion behavior to the synthetic polymers is limited. Given that nanofibers are to be used as cell matrices for tissue engineering, it is essential to confirm the initial cell adhesion and high population. Blending with natural polymers is another way of improving the cell compatibility $[57,58]$. When PCL was mixed with gelatin at a $1: 1$ ratio, the blending nanofiber exhibited good penetration of BMSCs within the nanofiber matrix. On the other hand, there was little growth observed within the pure PCL nanofiber [57]. Our recent study on the blending nanofibers of PLA with gelatin at various ratios (1:3, 1:1 and 3:1) showed that the osteoblastic cells (MC3T3-E1) were more viable than those on pure PLA nanofiber [58]. Moreover, a range of bonerelated genes were expressed at significantly higher levels on a blended hydrophilic nanofiber substrate. Another report developed heparan sulfate-containing PCL nanofibers, where human MSCs precommitted to an osteogenic lineage were observed to secrete bone matrix and bone formation under a subcutaneous model in nude mice [59]. Together with the blending approach, the surface of the synthetic nanofibers was coated with natural polymers, such as collagen and gelatin, which showed good initial adhesion and growth of cells including osteoblasts [60,61].

As natural polymer sources, collagen has long been studied for the electrospinning into nanofibers [62-64]. Type I collagen is the major organic component of bone ECM, and has attracted considerable attention for use as a bone cell supporting matrix. Nanofibers of collagen type I can be electrospun to various diameters and provide good substrate conditions for BMSCs to adhere and grow [63].
Although electrospun collagen mimics the nanofibrous morphology of native ECM, there is some debate as to whether the native structure and biological characteristics are preserved [64]. Whilst one report showed native periodic bands in electrospun collagen [62], Jeugolis et al. insisted the electrospun collagen was only a denatured form gelatin, when electrospun out of fluoroalcohols which limit the typical biological properties of collagen derived from the triple helical structure, and suggested the method of collagen coating of the electrospun nanofibers [64]. Nevertheless, cross-linked electrospun collagen is believed to have strong potential as a nanofibrous substrate for cells to anchor and populate as well as in osteogenic development and mineral deposition provided appropriate differentiation cues are present.

Silk fibroin has also been explored as a potential electrospun substrate because of its useful properties for tissue engineering, such as cell compatibility, biodegradability and minimal inflammatory reaction [65]. Electrospun nanofibers of silk with sizes ranging from $500 \mathrm{~nm}$ to $1 \mu \mathrm{m}$ were observed to support the initial adhesion and growth of BMSCs [65] and osteoblastic cells [66]. One merit of silk fibroin in bone regeneration is its ability to promote the deposition of calcium phosphate minerals thus to form an apatite-silk nanocomposite [67].

Compared to other natural polymers, chitosan is considered relatively difficult to electrospin mainly due to the limited solvents and high viscosity at low concentrations [68]. A recent study developed an electrospun chitosan nanofibrous mesh for use as a dental barrier membrane to selectively guide hard tissues within the periodontal pocket. The in vivo result at 4 weeks of implantation using the membrane within a critical-sized defect of a rabbit calvarium demonstrated almost full coverage of the defect and bone formation, which highlights its potential use in bone regeneration (Fig. 3) [69].

\subsection{Inorganic nanofibers}

Although the degradable polymeric nanofibers with a synthetic or natural origin have been shown to support the growth of osteoblasts and their progenitor/stem cells as well as to recruit their phenotypic expression and differentiation under the appropriate microenvironment, bone-bioactive inorganics, including calcium phosphates and bioactive glasses/glass ceramics have been a fascinating choice of materials for the reconstruction of hard tissues. In practice, the electrospinning of inorganic materials into a nanofibrous structure is well documented, even though they were mainly not for biomedical purposes. It was not until a few years ago that some studies exploiting

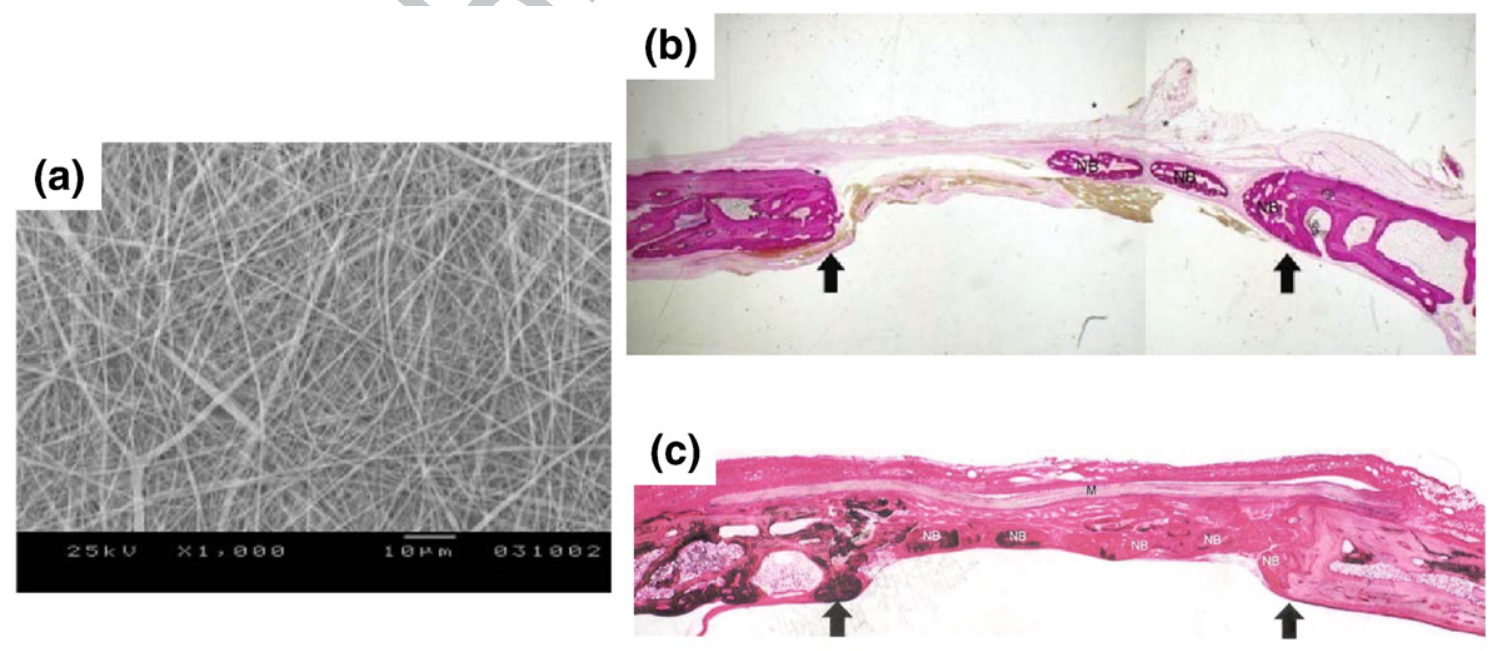

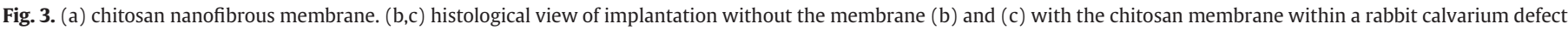

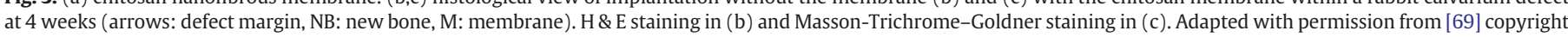
2007 American Academy of Periodontology. 
the bone-bioactive inorganic composition into electrospun nanofibers were reported.

A recent study reported the generation of bioactive glass nanofibers by electrospinning [70]. Silica-based sol-gel glass $\left(70 \mathrm{SiO}_{2} \cdot 25 \mathrm{CaP} \cdot 5 \mathrm{P}_{2} \mathrm{O}_{5}\right)$ mixed with a polymer binder was electrospun into a nanofibrous mesh and heat-treated to produce fibers with sizes ranging $84 \mathrm{~nm}$ to $640 \mathrm{~nm}$ by varying the sol concentration. The glass nanofiber induced the formation of a bone mineral-like apatite phase on the surface in a simulated body fluid, which was attributed to the extremely large surface area of the nanofiber and the consequent ionic reaction with the surrounding medium (Fig. 4). Moreover, the nanofibrous substrate actively supported a population of rat BMSCs and osteogenic differentiation to a level significantly higher than that on dense sintered bioactive glass or PCL polymer nanofiber, highlighting the potential of bioactive glass nanofibers in terms of both morphological and compositional benefits. A parallel approach has also been realized on the production of a range of inorganic nanofibers including hydroxyapatite [71-73], fluorohydroxyapatite [71], and silica nanofibers [74], by using the sol-gel solution which was mixed with a polymeric binder either with poly (vinyl pyrrolidone) and poly(vinyl butyral) and subsequent heat treatment. One elegant study applied the in-situ mineralization behavior of the bioactive glass to the introduction of biomolecules on the
501 502 503 504 505 506 507 508 509 510 511
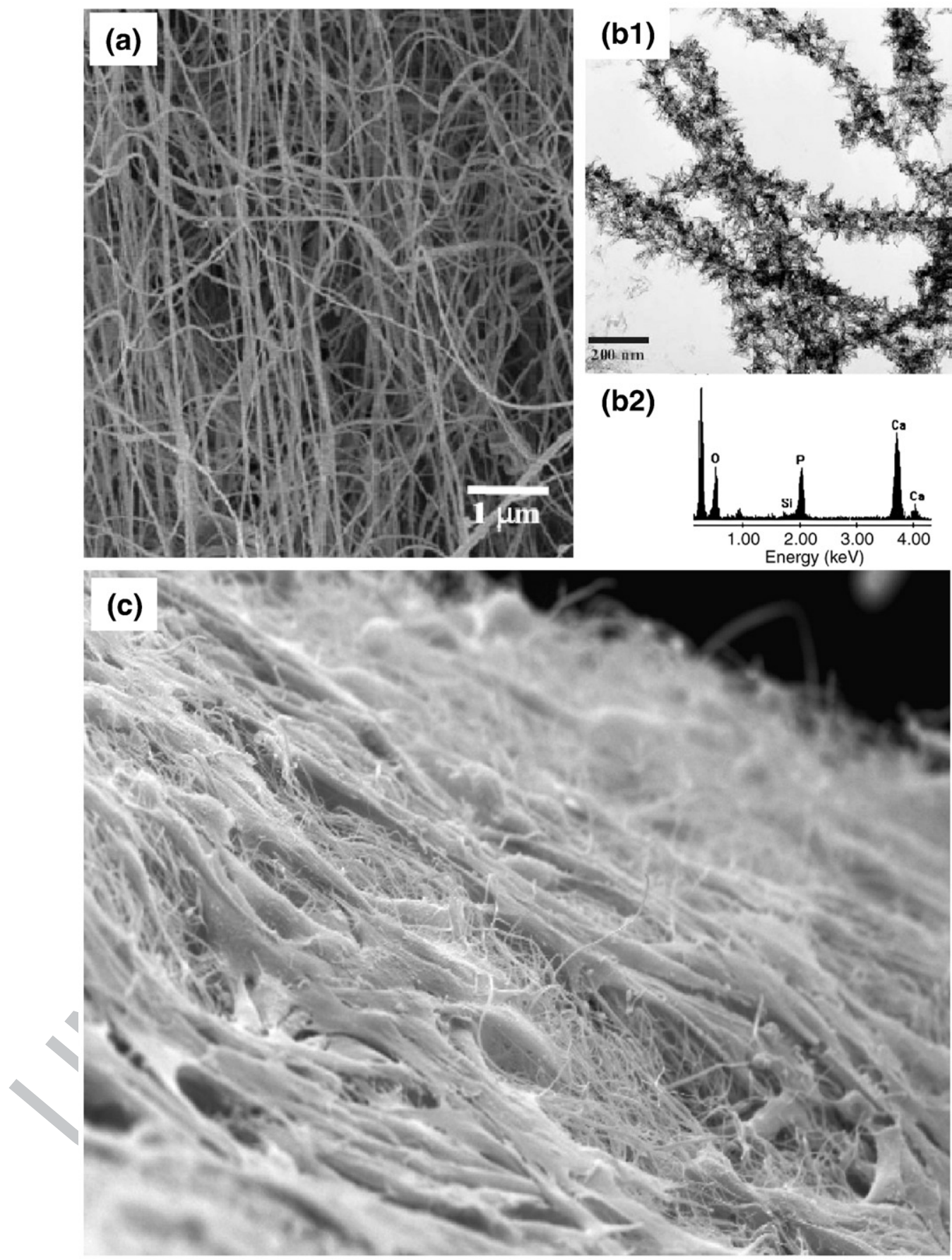

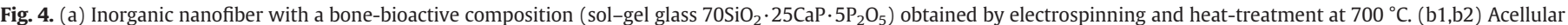

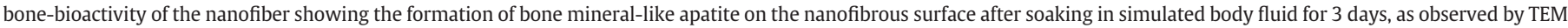

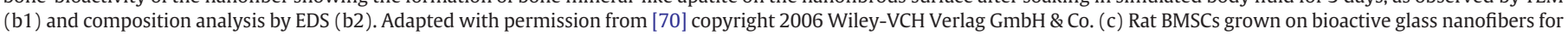
7 days exhibiting good cell population and active cytoplasmic extension in concert with the underlying nanofibrous substrate. 
nanofiber surface [75]. Cell-adhesive fibronectin was effectively coupled with apatite mineral onto the surface of bioactive glass nanofiber which demonstrated significant enhancement in the initial osteoblast adhesion and spreading.

However, regardless of their attractive bone-bioactivity, electrospun nanofibers of inorganic materials, including calcium phosphates and bioactive glasses, may have limited use as tissue regeneration matrices on account of their brittleness. Moreover, post heat-treatment can limit their drug delivery potential. In this respect, future knowledge and advanced technology need to be developed in order to overcome the disadvantages of bone-bioactive inorganic nanofibers as well as to identify appropriate uses as bone tissue engineering matrices. At the moment, nanofibrous inorganic materials are being studied as nanofillers for the production of nanocomposite scaffolds with degradable polymers $[76,77]$. In particular, electrospun nanofibrous bioactive glass, being used as a novel inorganic nanocomponent, is well homogenized with collagen or a PLLA solution to produce uniform scaffolds and membranes, ultimately improving the bone-bioactivity of the organic phase and osteogenic differentiation and cellular mineralization (Fig. 5). The approach, which aimed to combine the bone-bioactivity of the inorganic component with shape-formability of the organic phase, highlights the useful application of the electrospun inorganic nanofibers as a bone-bioactive nanocomponent.

\subsection{Polymer-inorganic composite/hybridized nanofibers}

Combining degradable polymers with bioactive inorganic materials during the course of electrospinning is considered a fascinating and reasonable way of generating nanofibers with the appropriate properties targeted for bone regeneration. The inorganic phase may act to improve the biological properties of polymeric nanofibers, such as cell compatibility and bone forming process, involving the osteogenic differentiation and calcification of bone matrix. Moreover, given that the brittleness of inorganic materials is a major limitation to their use as suitable cell substrates, the introduction of a polymeric phase should provide some degree of mechanical flexibility. In addition, the fact that there is no need for thermal treatment because of the binding polymer matrix is another attractive point for its use in drug delivery systems. Basically, the bone ECM is a type of composite constituted mainly of collageneous fibers embedded with hydroxyapatite nanocrystallites, which highlights the need for the development of nanocomposites mimicking bone structure [35].

In practice, the combinatorial/synergistic mechanical and biological properties of polymers and inorganics have been well documented in cases of porous scaffolds and membranes [78]. The ideas beyond those nanocomposites might well be applied to nanofibrous systems. However, it should also be noted that the electrospinning of organicinorganic compounds requires special consideration in the preparation of solutions. Some elegant methods have been used to produce organicinorganic composite nanofibers by electrospinning. One example is the gelatin-hydroxyapatite nanofiber, which was designed to mimic the bone ECM, wherein gelatin and hydroxyapatite precipitates were dissolved in an organic solvent and subsequently electrospun to produce nanofibers with, hundreds of nanometers in diameter (Fig. 6) [79]. Hydroxyapatite nanocrystallites were evenly distributed in the gelatin matrix within the nanofibrous morphology, which was
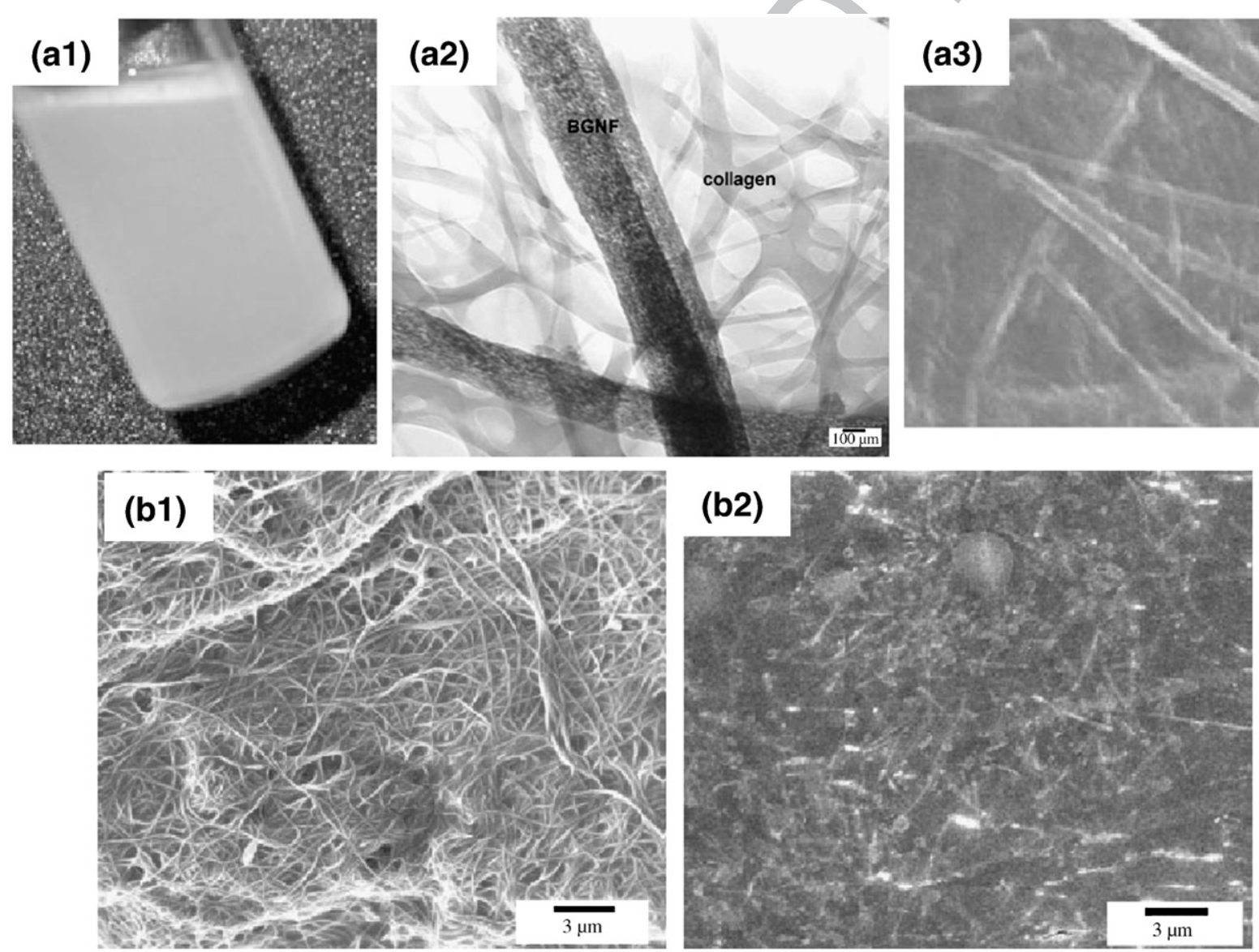

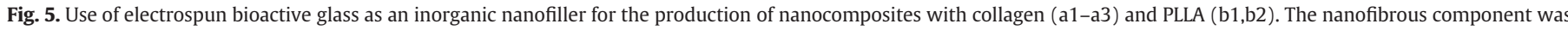

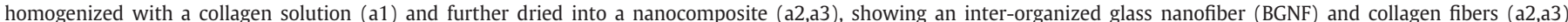

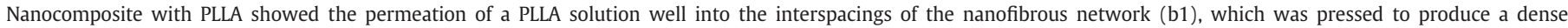

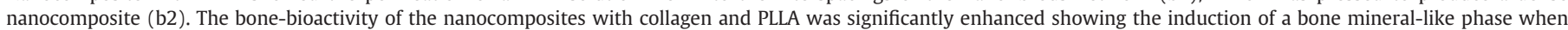
immersed in SBF. Adapted with permission from [76,77] copyright 2007 Wiley Interscience Co. 

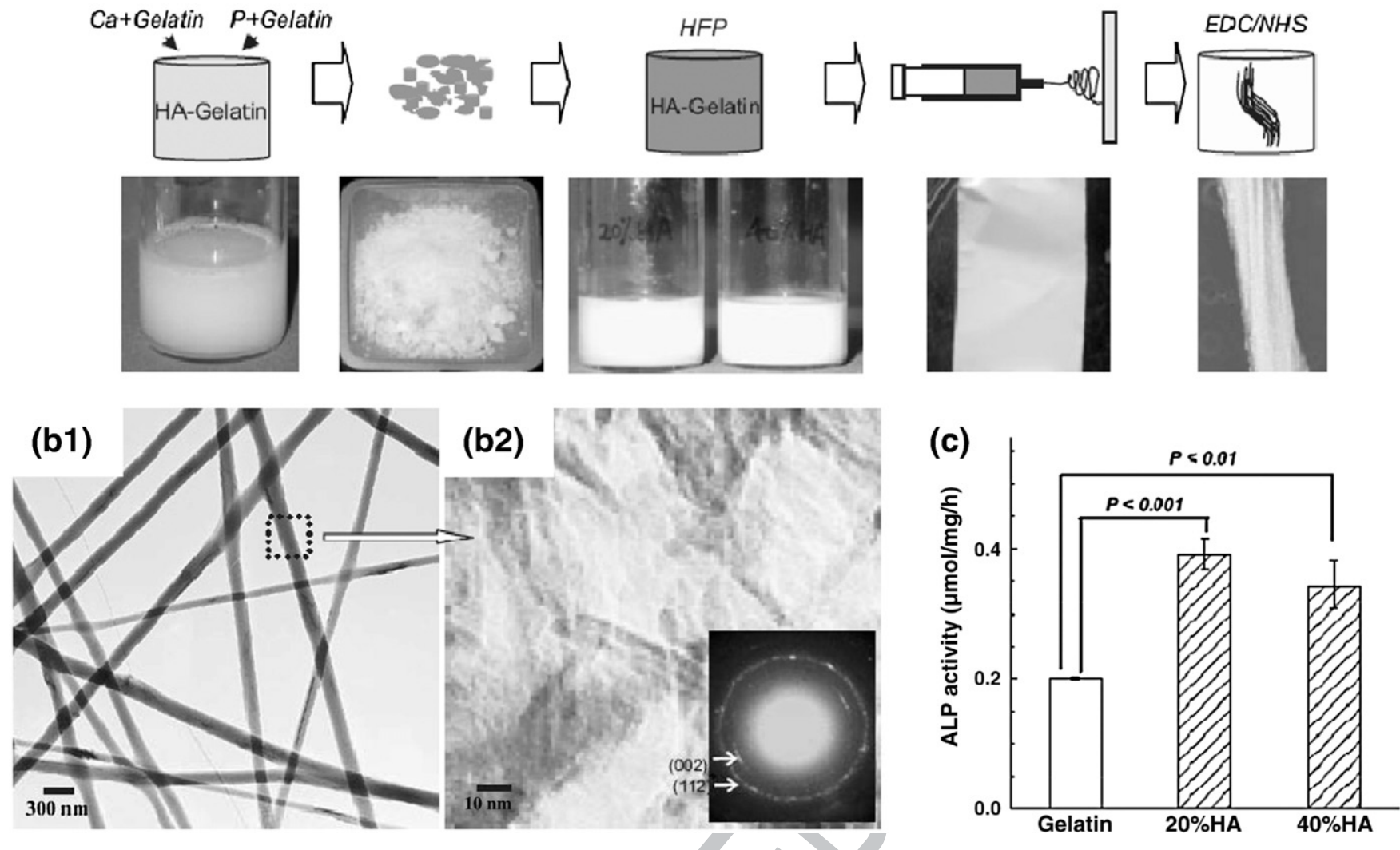

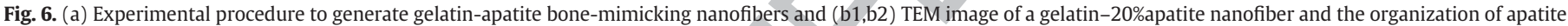

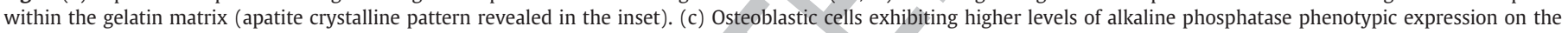
nanocomposite nanofibers after 7 days of culturing. Adapted with permission from [79] 2005 Wiley-VCH Verlag GmbH \& Co.

attributed to the role of the gelatin amino acid sequences modulating the precipitation of hydroxyapatite crystals. On the other hand, when hydroxyapatite nanopowders were mixed directly with a gelatin solution, electrospinning into nanofibers was impeded significantly resulting in a number of beads. The organized hybrid matrix showed significant enhancement in osteoblastic differentiation, and was proposed for use as a guided tissue regeneration membrane in dentistry. This approach was also realized in the collagen-hydroxyapatite system to generate a nanofibrous matrix to better mimic the bone ECM [80] as well as applied to other composite nanofiber of chitosan-hydroxyapatite [81].

Apart from natural polymers, synthetic degradable polymers have also been used in the electrospinning of composite fibers with bioactive inorganic materials. However, unlike hydrophilic natural polymers, which are easier to homogenize and be organized with inorganic crystallites, degradable synthetic polymers, such as PLA, PCL and PHBV, present a significant challenge in their combination with the inorganic phases on account of their hydrophobic nature. A recent work by Fujihara et al. developed $\mathrm{PCL}-\mathrm{CaCO}_{3}$ composite fibers with submicrometers in size, by introducing ultrafine $\mathrm{CaCO}_{3}$ particles $(\sim 40 \mathrm{~nm}$ in size) [82]. Composite fibers containing $\mathrm{CaCO}_{3}$ nanoparticles at 25 and $75 \mathrm{wt} \%$ showed good water affinity and mechanical tensile properties, as well as directed favorable osteoblastic adhesion and growth, thus being suggested for use as a guided bone regeneration membrane (Fig. 7).

However, inorganic nanoparticles generally agglomerate easily and cannot be intermixed well or homogenized with synthetic polymer solutions, resulting in bead formation during electrospinning. In an attempt to overcome this, we recently exploited PLA composite fibers containing ultrafine hydroxyapatite nanocrystallites obtained by a sol- gel process ( $35 \mathrm{~nm}$ in size) and by introducing a surfactant, 12 hydroxysteric acid (Fig. 8) [83]. The amphiphilic nature of the surfactant was suggested to act as a stabilizing mediator at the interface of the hydroxyapatite nanocrystallites and PLA-organic solvent. Bead-free electrospun fibers were obtained with fiber sizes of a few micrometers wherein the hydroxyapatite nanocrystallites well distributed within the PLA matrix. The composite fiber was shown to promote the growth of osteoblastic cells and their phenotype expression to a significantly higher level than on pure PLA fiber. Overall, the current electrospinning of composite fibers has focused mainly on incorporating bioactive inorganic nanoparticles evenly within a polymeric matrix without breaking down the fibrous morphology. This has been possible to a large extent through the introduction of ultrafine particles or control of the level of homogenization.

Instead of introducing particulate forms of the bioactive inorganic phases within a polymeric solution, degradable and bioactive hybrid nanofibers were recently produced through the hybridization approach of using inorganic and organic phases in solution, such as the sol-gel process [84]. An aqueous solution of gelatin was mixed with polysilane (3-(glycidopropyl) trimethoxysilane) at various ratios (siloxane/gelatin $=0.5,1$ and 2) containing a small concentration (2.5 wt.\%) of $\mathrm{CaCl}_{2}$, which was hydrolyzed, condensed and then electrospun into nanofibers. In particular, the involvement of siloxane groups within the gelatin significantly improved the chemical stability of gelatin by forming linkages with amide groups of gelatin to produce a hybridized network. Moreover, the hybridized nanofibers significantly enhanced osteoblastic differentiation, suggesting their potential use as a bone regeneration matrix (Fig. 9).

The approach of using bioactive inorganic phases in concert with degradable polymers is continuing to attract attention in finding
596 


\section{PCL Nano Fibers}

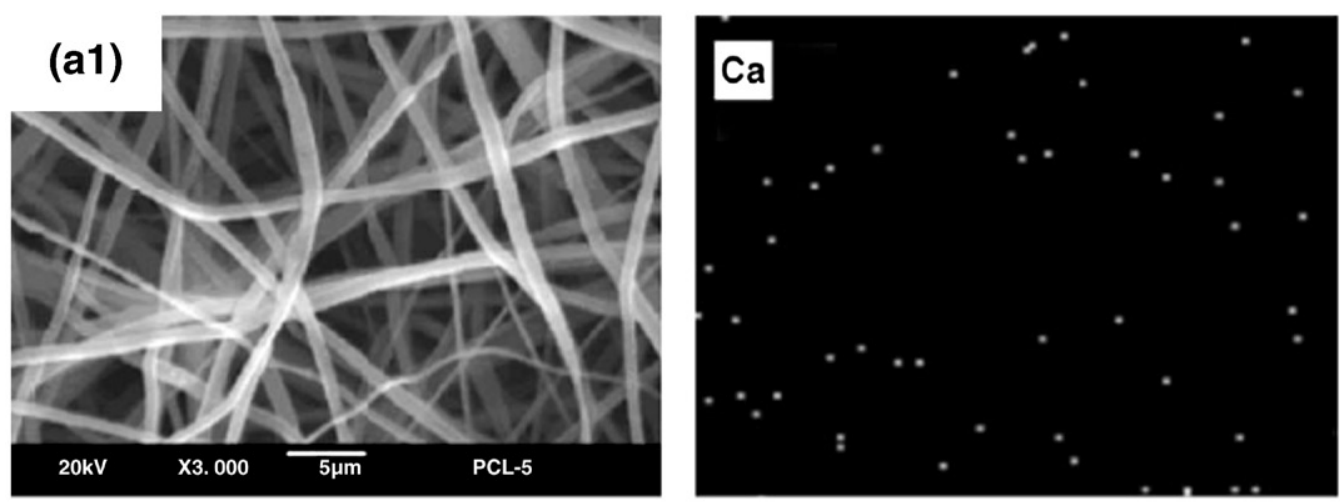

$\mathrm{PCL} \mathrm{CaCO}_{3}$ Composite Nano Fibers

(PCL : $\left.\mathrm{CaCO}_{3}=25: 75\right)$
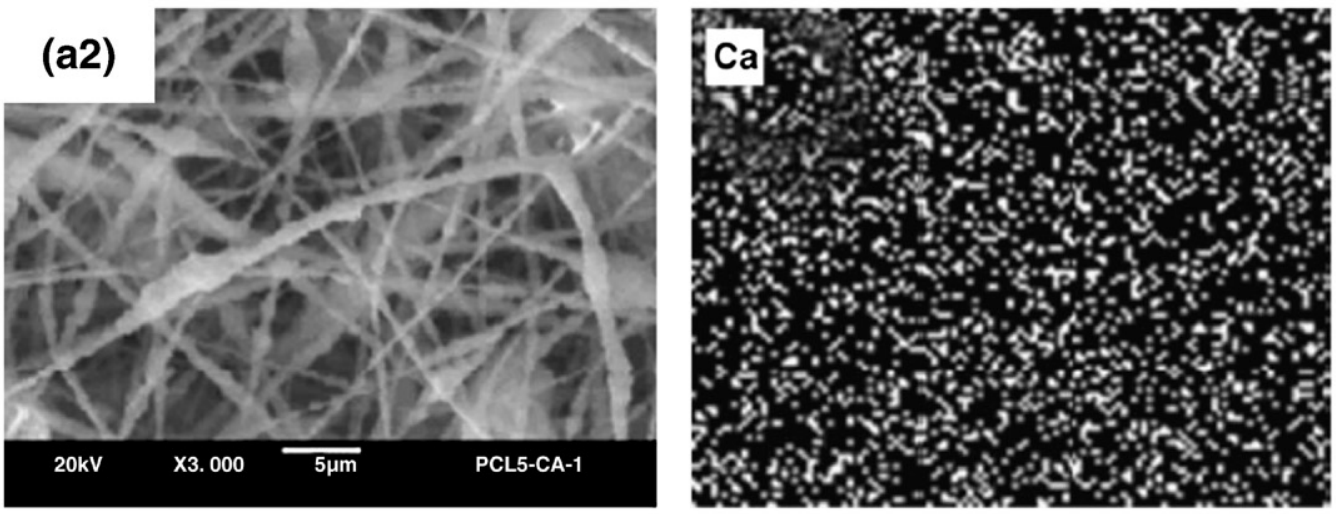

(b)
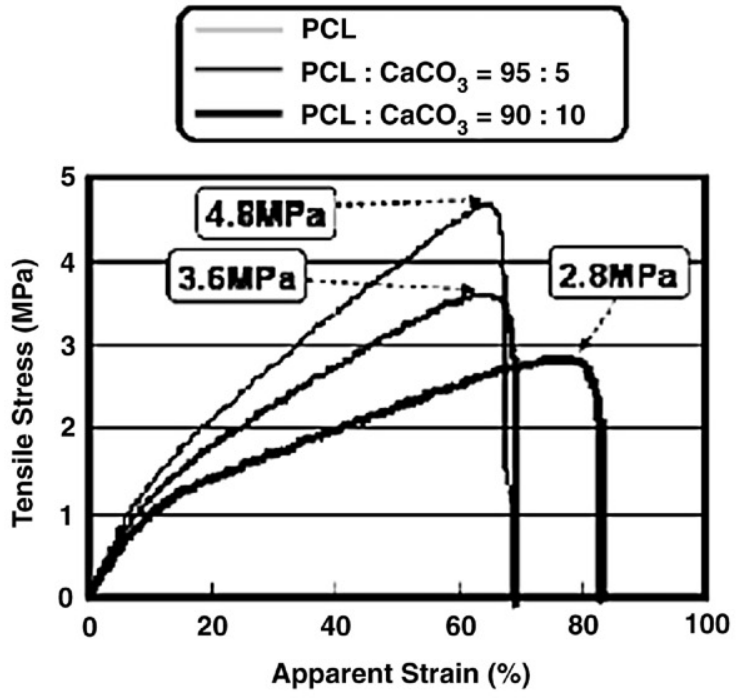

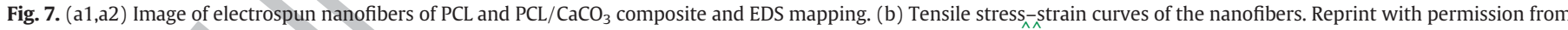
[82] 2005 Elsevier.

suitable matrices for the regeneration of bone and its interfaced zone with cartilage [85,86]. Therefore, many more studies are expected to focus on developing composite nanofibers with new compositions with suitable mechanical properties and biological functions in bone regeneration. Although some challenges still remain, such as morphological and compositional control, including a reduction of fiber size, level of homogenization, and securing mechanical stability, more promising results are expected to come out from the composite nanofibers with respect to the polymeric single component.
4. Bio-functionalization and scaffolding for tissue engineering

Given that nanofibrous matrices have an extremely large surface area relative to volume, the surface-related properties of nanofibrous materials, such as materials release, protein adsorption and cell adhesion, are very important. Therefore, it is essential to tailor the surface properties of nanofibers to induce the appropriate biological reactions. The surface-functionalization of the nanofibers, as a posttreatment following the electrospinning process is another important 
(a)

HA in HSA -Chloroform
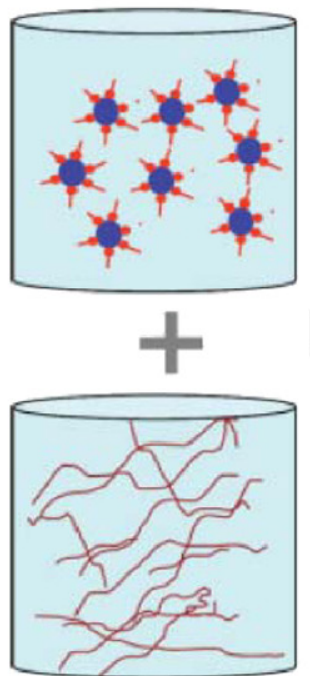

PLA in chloroform
Nanocomposite solution
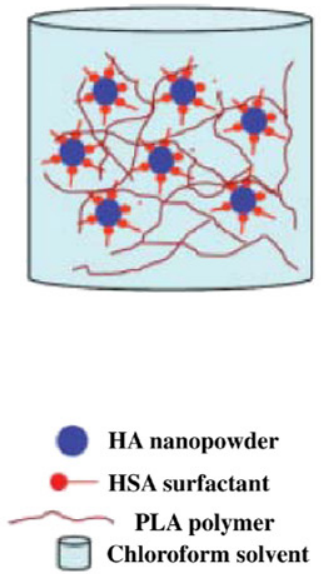
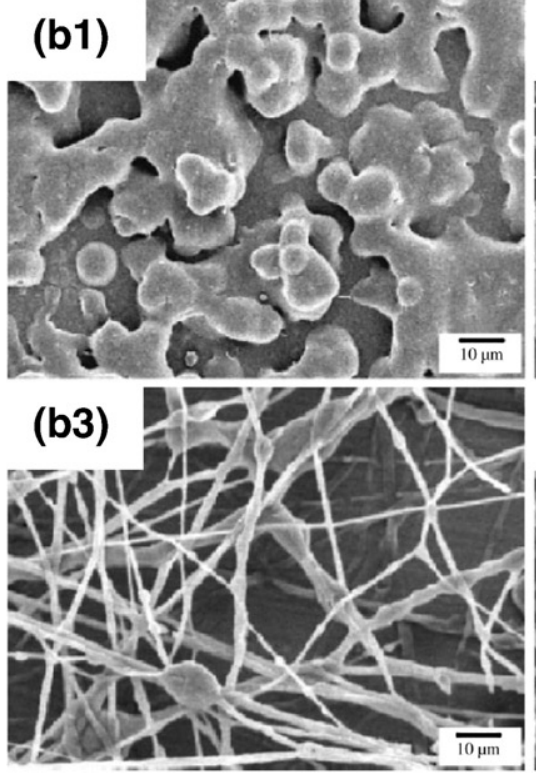

(b2)

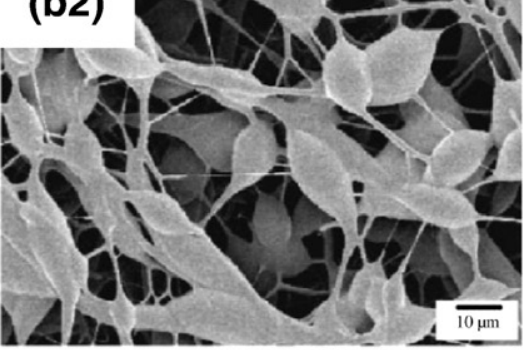

(b4)

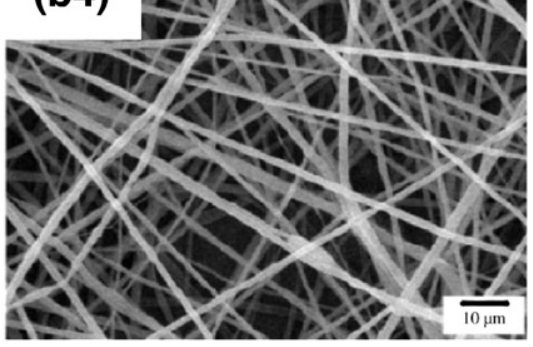

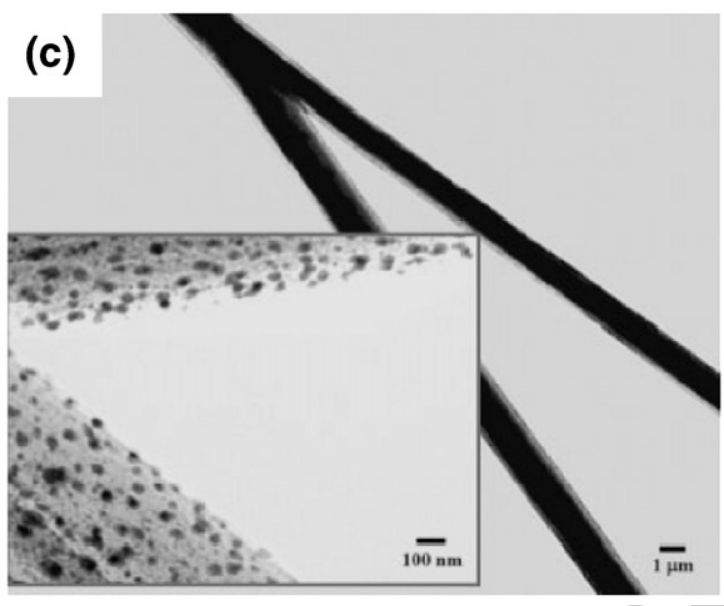

(d)

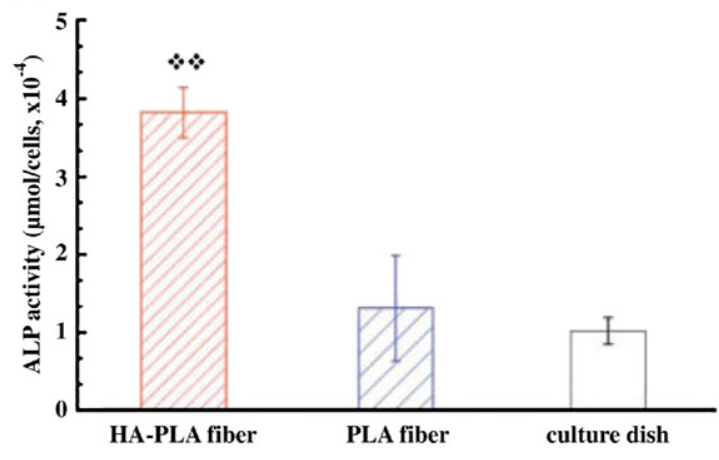

Fig. 8. (a) Schematic diagram showing the experimental design of the HA-PLA biomedical nanocomposite fiber mediated with HSA surfactant through the electrospinning process. (b1-b4) Electron morphology of the HA-PLA nanocomposite fiber electrospun under different conditions: HA commercial powder without HSA (b1), HA sol-gel powder without HSA (b2), HA sol-gel powder with $0.1 \%$ HSA (b3), and concentration of (b4) $12.5 \%$ was thickened to $25 \%$ by evaporation of the solvent (b5). (c) TEM morphology of the nanocomposite electrospun fiber consisting of HA sol-gel powder and PLA obtained with the mediation of $0.1 \%$ HSA. Fiber image in the inset prepared as an ultrathin film ( $<100$ nm) using a microtome reveals the dispersion of HA fine particles within the PLA matrix. (d) ALP activity expressed by the cells after culturing for 7 days. A glass coverslip was used as a fiber-supporting substrate. Data on tissue culture dish was included as a control. The cell seeding density was $1 \times 10^{4} / \mathrm{ml}$. The data is reported as the mean \pm std., for $n=6$, and a statistical comparison by ANOVA one-way analysis showed significant differences between the HA-PLA fiber and PLA fiber at $p<0.01(*)$ and $0.001(* *)$. Reprint with permission from [83] 2006 Wiley Interscience Co.

area for regulating and improving the potential of nanofibers as a cell matrix. The initial cell adhesion and growth, osteogenic differentiation and matrix synthesis, and therapeutic stimulations can be tuned by bio-functionalization of the surface, which include the surface coverage with bone-reactive materials and spatially distributed conjugation with macromolecules, such as proteins, peptides and antibiotics. In the latter case, surface-tailored nanofibers will have therapeutic impact as an implantable drug delivery system [6]. However, in order to gain intended biological performance, the surface conjugated molecules should maintain their biological activity and exhibit therapeutic functioning in a timely and proper manner. However, in such systems for long term delivery, drugs sometimes need to be encapsulated within the nanofiber to elicit therapeutic effect in a sustained manner.

The improvement in 3D scaffolding techniques is another challenge in electrospun nanofibers if they are to find potential use in bone tissue engineering. Electrospun nanofibrous meshes contain small sized channels, at best a few micrometers in size, which can restrict cell migration and angiogenesis to form neo-blood vessels. Many recent attempts have been made to produce macropores within or to construct 3D tissue analogs with electrospun nanofibers, which may extend their potential use in bone tissue engineering.

\subsection{Surface functionalization}

Specific focus has recently been made on utilizing bone mineral phase in surface-tailoring of polymeric nanofibrous matrices which targeted for bone regeneration. As the bone mineral-like calcium phosphates, mainly hydroxyapatite phase, have good biocompatibility related to cell affinity and osteogenic regulation, a surface treatment of degradable polymeric nanofibers with a mineral phase is a promising route for up-regulating the bone cell functions [87-89]. A recent study mineralized a PCL nanofibrous surface with hydroxyapatite using a series of surface-modification steps involving the activation of 

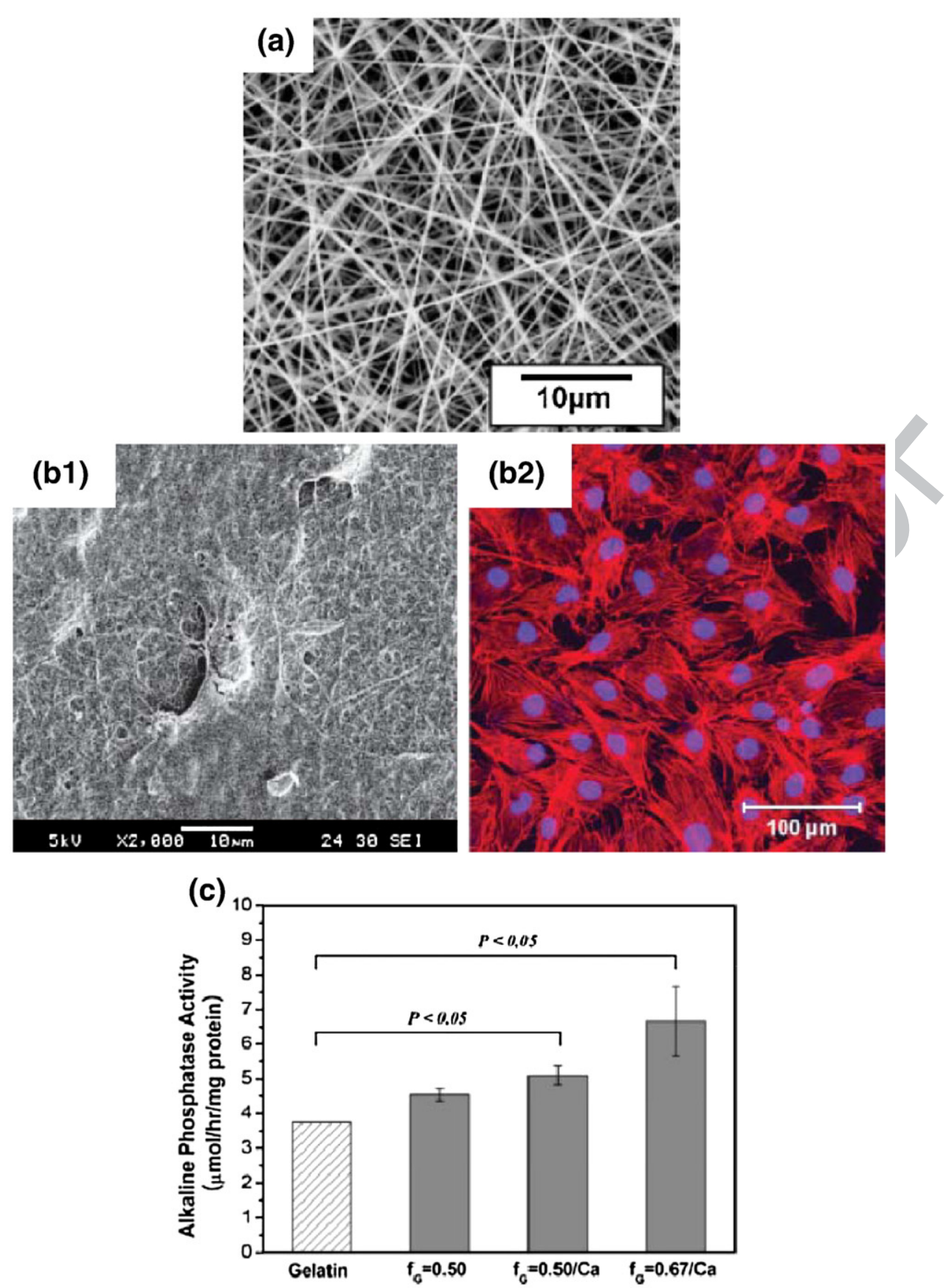

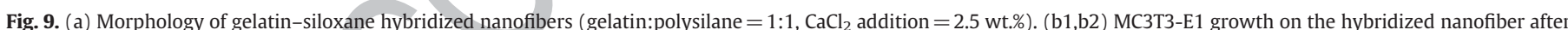

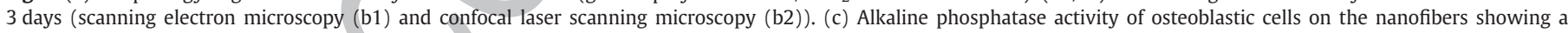
significantly higher level on the hybridized ones (ANOVA). Reprint with permission from [84] 2008 Wiley Interscience Co.

nanofibers in an alkaline solution ( $2 \mathrm{~N} \mathrm{NaOH}$ ) to generate carboxylic groups, followed by alternate dipping in $\mathrm{Ca}$ and P-rich solutions $\left(150 \mathrm{mM}\right.$ of $\mathrm{Ca}^{2+}$ and $\mathrm{HPO}_{4}^{-}$) to allow mineral nucleation followed by further soaking in a Ca-P pseudo saturated solution (simulated body fluid) [87]. The mineralized PCL nanofiber showed active osteoblastic responses, such as cell adhesion and growth, and significantly higher expression levels of the genes related to bone ECM than those on pure PCL nanofiber [87] (Fig. 10). Through surface mineralization, significant osteogenic induction was also observed on the periodontal ligament fibroblasts, highlighting the mineralized polymeric nanofiber for use as a guided bone regeneration membrane [88]

A similar approach has also been found in other degradable polymers, including PLA ( $L$ - and DL-type), wherein the mineral induction was facilitated more easily by treatment in an alkaline solution [89] or by incorporating calcium [90]. When collagen was added to the PLA nanofiber, hydroxyapatite induction was possible without treatment with an alkaline solution, where collagen plays a key role in mineralization [91]. The hydroxyapatite mineral phase obtained by the solution-mediated process is generally poorly crystallized and carbonated, being similar in composition and structure to the native bone mineral, which is thus believed to regulate a series of biological reactions in a favorable manner, including the selective adsorption of bone-associated proteins, osteogenic stimulation of progenitor/stem cells, and the acceleration of subsequent bone formation. Moreover, modification of mineralized nanofibers with bio-functional molecules is expected to be a promising area of future research because the apatite mineral has strong affinity to certain bone-specific proteins which contribute enhanced bonding to bone tissue $[92,93]$. 

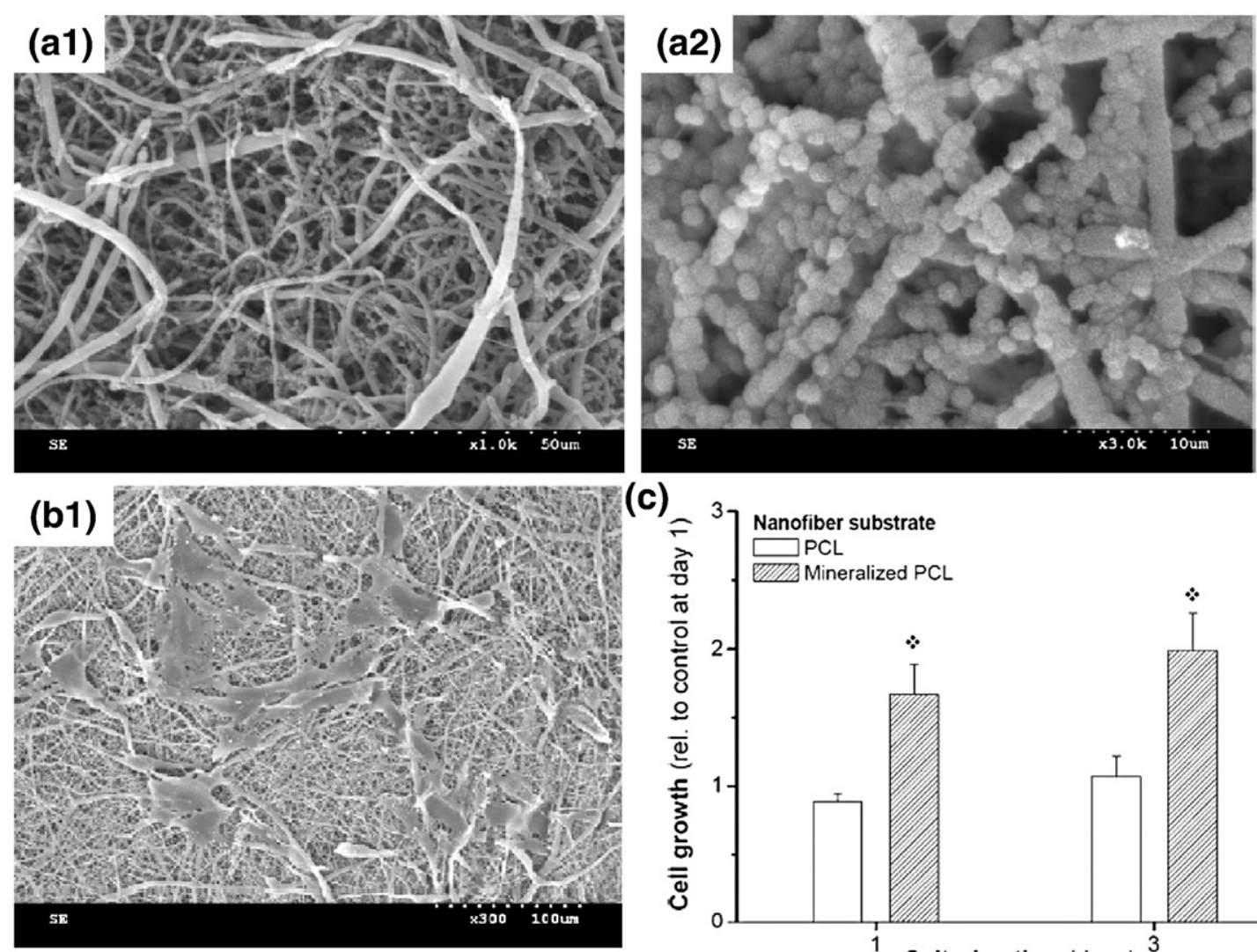

(c)
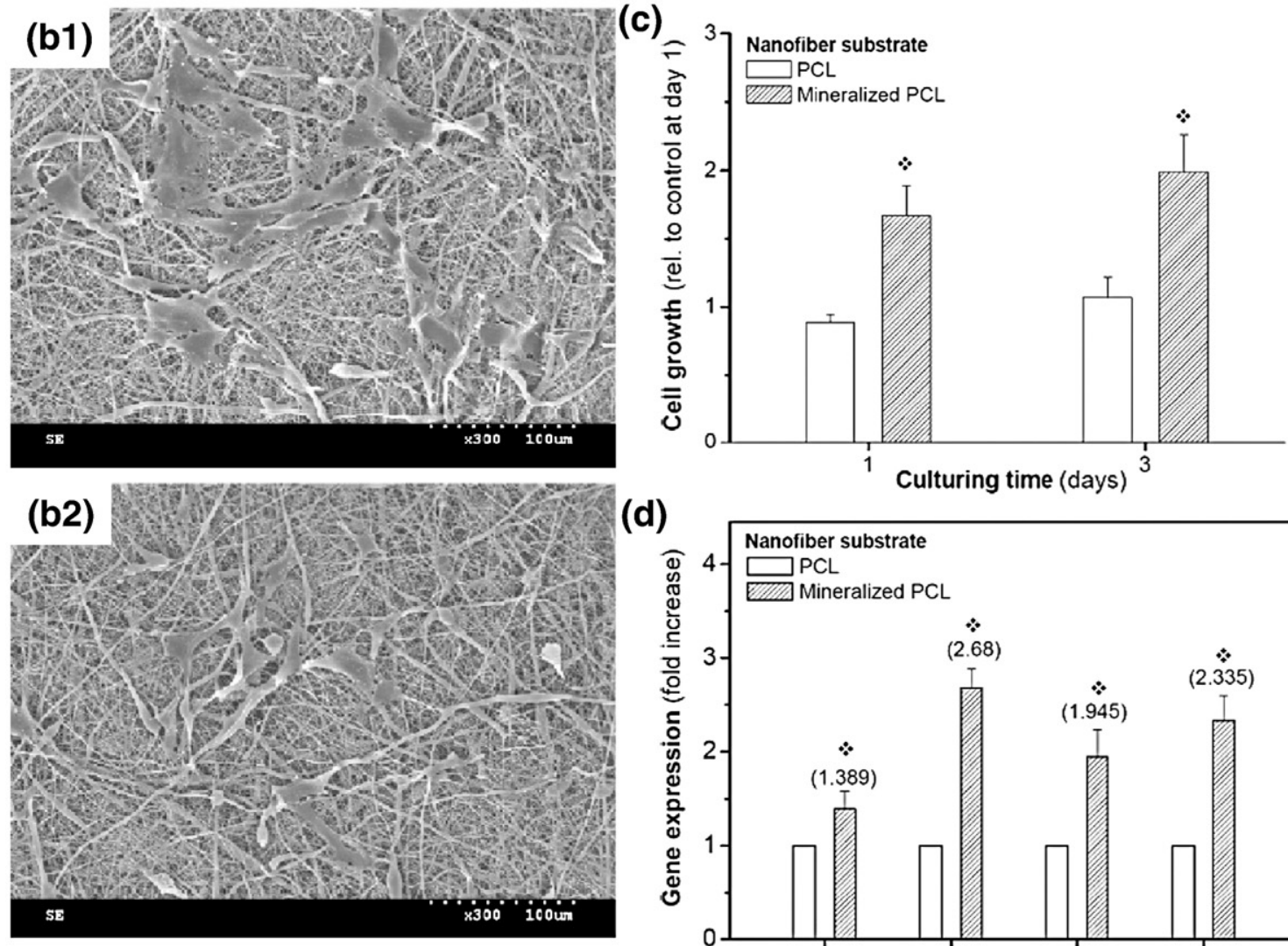

(d)

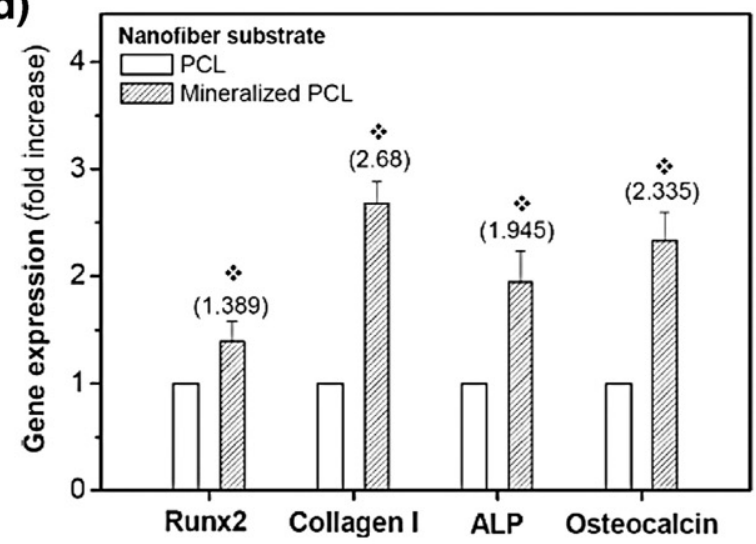

Fig. 10. (a1,a2) Morphology of the surface-mineralized PCL nanofibrous matrix obtained by a series of solution-mediated mineralization steps involving activation in an alkaline solution, alternate soaking in Ca- and P-solutions, and immersion in SBF. (b1,b2) Initial osteoblastic cell response showing better spreading behavior on the mineralized PCL nanofiber (b1) than on pure PCL nanofiber (b2) at $8 \mathrm{~h}$ of culturing. (c) Cell viability and (d) expression of bone-associated genes were significantly enhanced by surface mineralization. Adapted with permission from [87] 2007 Wiley Interscience Co.

More general than the mineral phase is the bioactive macromolecules that have been introduced on the surface of polymeric nanofibers, including proteins, peptides and drugs, to regulate and improve specific biological functions. Nonetheless, few studies have examined the applicability of macromolecules in bone regeneration area. A few studies used RGD (Arg-Gly-Asp) peptides to adhere onto polymeric surfaces and reported the biological effects of the cell adhesive ligands, such as adhesion, spreading and growth, using a range of cell types $[94,95]$. Fibroblast adhesion, spreading and growth were enhanced when the GRGDY peptide was immobilized on PLGA and its copolymer with PLGA-b-poly(ethylene glycol) (PEG)- $\mathrm{NH}_{2}$ nanofiber [94]. Given that the major weakness of the synthetic polymeric surface is the poor cell affinity, the use of adhesive proteins or peptides is believed to be an appropriate way of improving the initial bone cell responses and possibly further biological steps. Our recent study also developed the surface of poly(lactic-co-caprolactone) (PLCL) nanofibers by covalently linking with a fibronectin peptide containing a central cell binding domain to improve the initial cell adhesion and spreading behavior of osteoblastic cells. Parallel applications were also suggested using bone target proteins and peptides, such as growth factors and bone morphogenetic protein family. Together with the types of macromolecules, the selection of a coupling method and the maintenance of their biological activity should be fully considered to gain the optimal performance of biomolecules on a nanofiber surface.

\subsection{Drug encapsulation within nanofibers}

When macromolecules are coupled onto the surface of nanofibers, maintenance of their chemical stability and biological activity for prolonged time course is of special importance. Therefore, the
718 719 720 721 722 723 724 725 726 
encapsulation of drugs within the nanofibers might be favored, which will be particularly useful for controlled release systems. In this case, the encapsulation method and drug efficiency as well as the eluting profiles need to be designed and investigated carefully. In particular, the drugs chemically bound to the matrix with respect to those physically mixed/ adsorbed may sustain their elution for longer period, and depending on the encapsulated status, drug release kinetics is greatly affected. A range of drugs have been encapsulated within the nanofibers of polymers, including antibiotics, bone morphogenetic protein, and even genes [96101]. Although not all were targeted for bone tissue, the method is believed to be suitable for bone reconstruction. Poly(lactic-co-glycolic acid) (PLGA) nanofibers mixed with a hydrophilic block copolymer were incorporated with antibiotics (Mefoxin ${ }^{\circledR}$, cefoxitin sodium), and the nanofiber mesh showed potential to entrap drugs and then release them in a sustained manner, ultimately inhibiting bacterial activity $[96,97]$. For the specific delivery of osteogenic signals, BMP-2 was encapsulated directly within the blending polymer of silk and polyethylene oxide to show enhanced mesenchymal stem cell differentiation into the osteogenic linage and calcification [98]. For gene delivery within the nanofibrous matrix, DNA was first encapsulated within a block copolymer polylactide-poly(ethylene glycol), which was further electrospun in concert with the PLGA solution [100]. The results showed that the nanofibrous matrix delivered DNA that was capable of cellular transfection and encoding protein $\beta$-galactosidase [100]. Recent

(a)

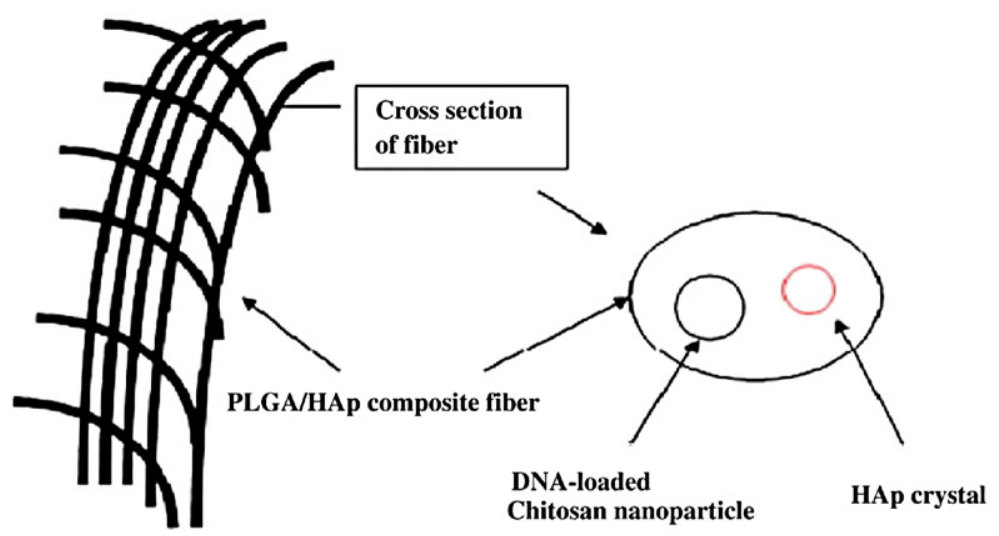

\section{PLGA/HAp composite fiber with DNA-loaded Chitosan nanoparticles encapsulated inside}
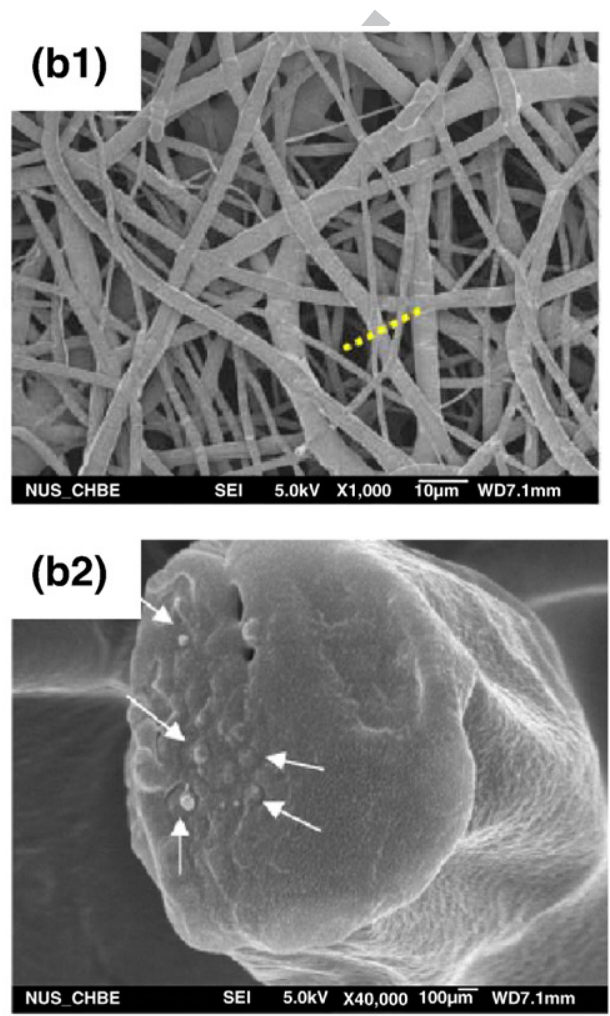

(c)

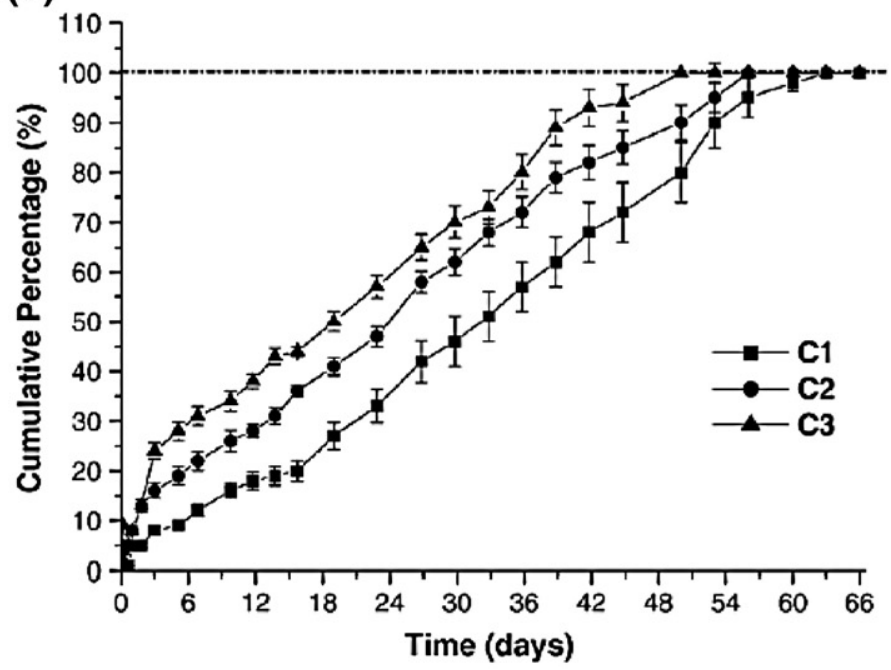

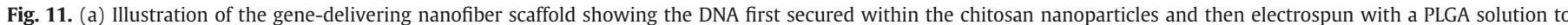

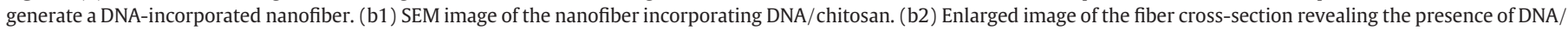

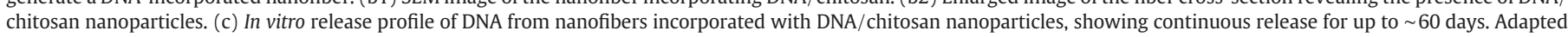
with permission from [101] copyright 2007 Elsevier. 
study on specific targeting for bone tissue has been reported by Nie et al., where they used the PLGA/hydroxyapatite composite nanofibers to deliver BMP-2 plasmid DNA [101]. In particular, the DNA was preloaded within chitosan before electrospinning the PLGA/hydroxyapatite solution. The results demonstrated that the nanofiber encapsulated with DNA/chitosan had higher cell attachment and viability as well as more desirable transfection efficiency than the nanofiber surfaceadsorbed with naked DNA or surface-adsorbed with DNA/chitosan (Fig. 11) [101]. Pre-encapsulating genes within nano-vehicles before electrospinning is thus considered an appropriate way of securing the biological stability of genes and improving the transfection efficiency. Although studies on gene delivery with nanofibrous matrices are still in the early stages, this area may be a future direction in the bone regenerative medicine using the nanofibers [102].

Novel designing of the electrospinning apparatus permits advances in the drug delivery technology. A dual tip (syringe) apparatus, so-called co-axial electrospinning, which was designed to produce a core-shell structure of the nanofiber, was reported to contain and release drugs more efficiently $[103,104]$. Drug-containing solution to be placed in the core part was electrospun simultaneously with the material solution to be allocated at the outer layer. In this case, while the inner solution affects the drug loading efficiency and stability, the properties of the shell layer can control the drug release profile. Furthermore, depending on the drug properties, suitable materials and solutions should be selected for the core-shell nanofiber structure. Modulation of the morphological and chemical properties of nanofiber materials is the key to controlling the drug delivering ability [9]. This drug delivering potential greatly strengthens the ability of artificial scaffolds to guide osteogenic differentiation of stem cells and to generate bone analogs in bone tissue engineering approach. As new knowledge on novel materials becomes available, more extensive works are expected in tissue engineering nanofibrous scaffolds with therapeutic design targeted for bone.
771 772 773 774 775 776 777 778 779 780 781 782 783 784 785 786

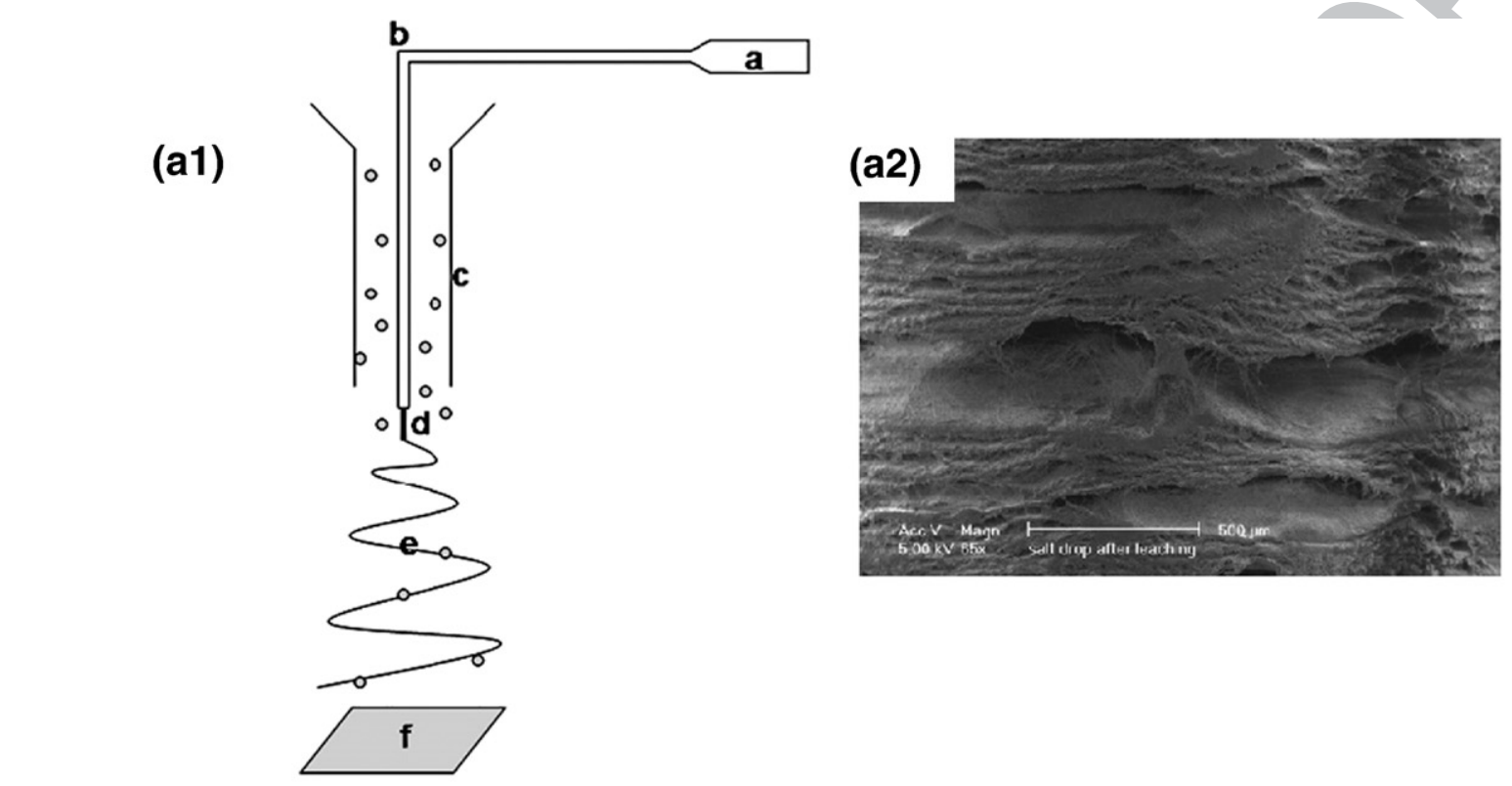

(b1)
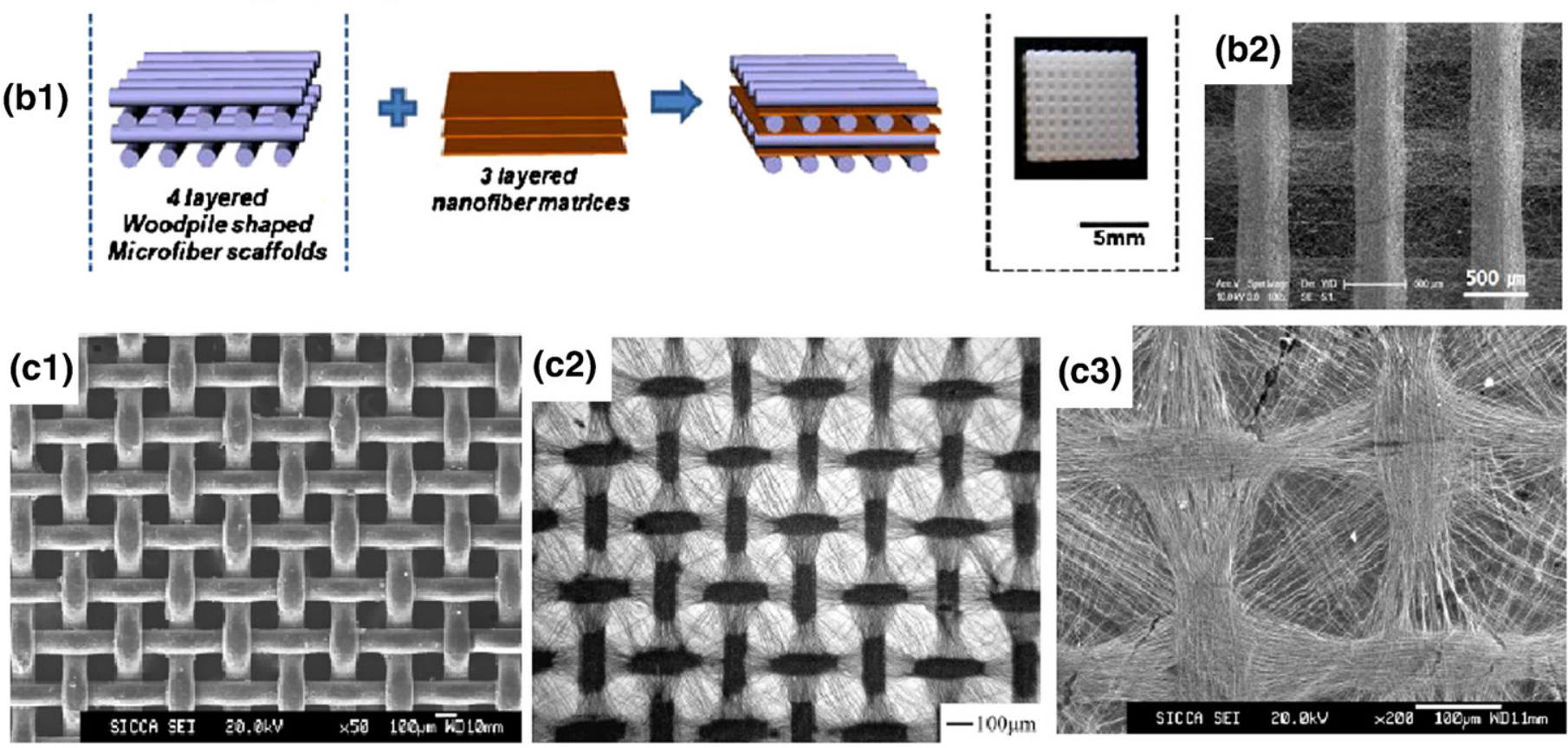

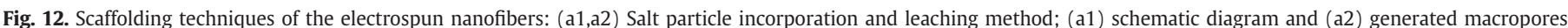

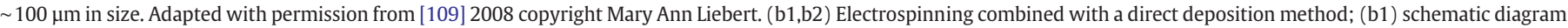

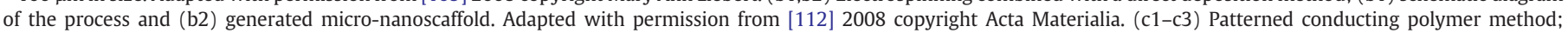
(c1) knitted conducting polymer collector and (c2,c3) produced patterned scaffolds. Adapted with permission from [113] 2007 copyright Wiley-VCH Verlag GmbH \& Co. 


\subsection{Scaffolding for cell growth and tissue engineering}

More widespread use of electrospun nanofibers for tissue engineering applications has been a challenge due to their difficulty in 3dimensional shaping and macroporous scaffolding. Processed by a type of line-of-sight approach, electrospun fibers are first gathered in the form of a 2-dimensional sheet and then piled up 3-dimensionally with increasing spinning time. Although some collector designs help shape nanofibers into simple forms, such as tubular forms, much more complex shapes are still on demand [105]. Above all, interconnected macro-pores are essential for vascularization in order to supply oxygen and nutrients, provide sufficient space for cell ingrowth and drain the consumed metabolites [106,107]. Although the electrospun nanofibrous structure generates a network of open-pores, the pore sizes are about the same order of the fiber sizes, i.e., at best a few micrometers. Some studies provided evidence of in vitro cell penetration and in vivo tissue formation within the nanofibrous network, where thin membranous substrates were used [57,108]. In particular, the ex-vivo culturing of 803 tissue cells within nanofibers to construct uniform cell-material 804 constructs is a significant challenge. Moreover, the reconstruction of 805 larger and complex-shaped bone defects requires 3-dimensional 806 shaping of the nanofibrous scaffolds with interconnected macropores. 807 Otherwise, new technological tools to develop 3-dimensional tissue mimicking cell-nanofiber constructs should be explored.

Some studies have reported a level of success on the scaffolding of electrospun nanofibers [109-113] (Fig. 12). Salt particles were incorporated within the polymer nanofibrous matrix, which then leached out to generate some macropores [109]. Furthermore, salt leaching and gas foaming techniques have been combined to produce some macropores within a clay-reinforced PLA nanofibrous structure [110]. One approach used the microfibrous mesh as a rigid supporting structure upon which the nanofibrous network was covered by electrospinning to produce a micro-nano fibrous scaffold [111]. However, the process can only produce a scaffold with a limited

(a)

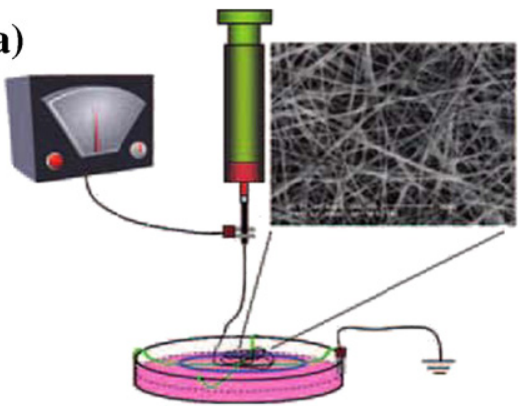

Step 1:Fiber spinning (1 layer fiber)

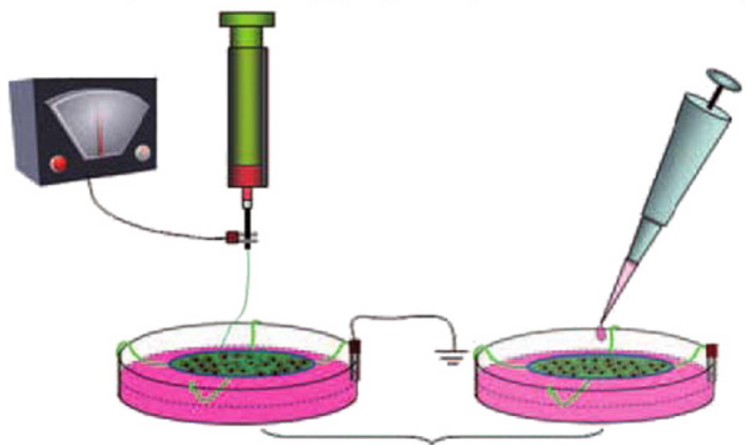

Repeat Step 1\& Step 2 until desirable layers of fibers and cells

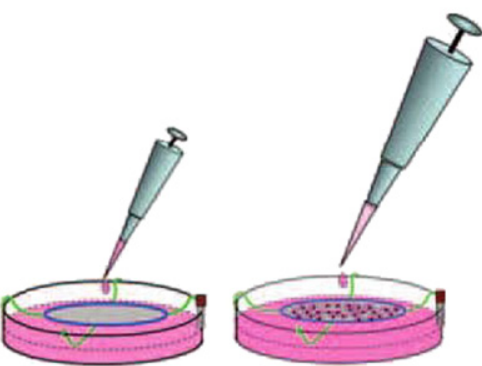

Step 2: Cell seeding (1 layer cell)

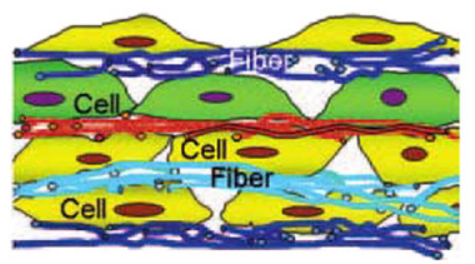

On site layer-by-layer tissue generation

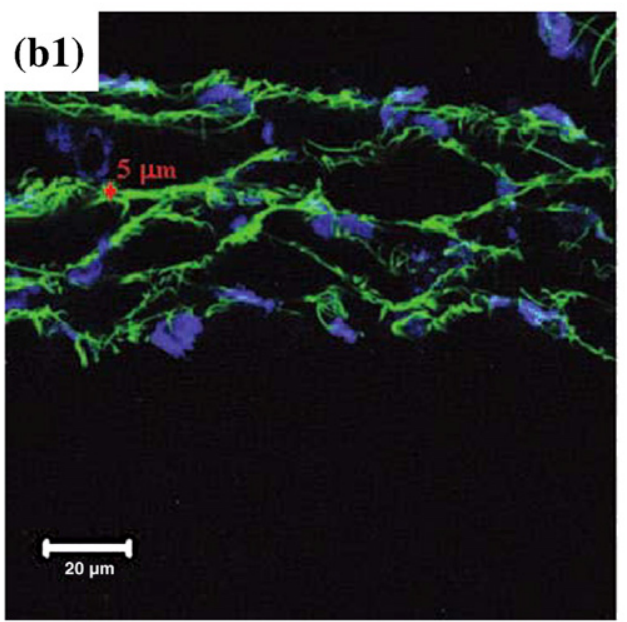

(b2)

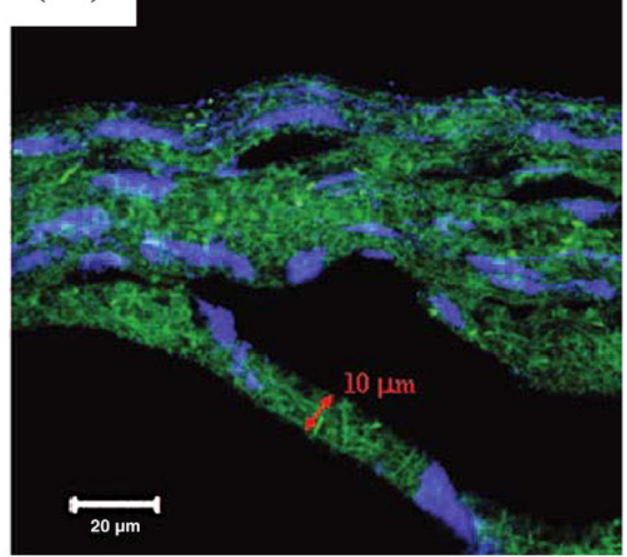

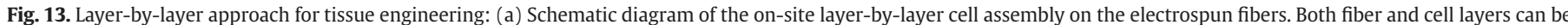

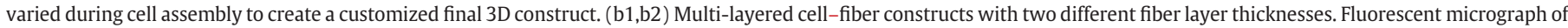

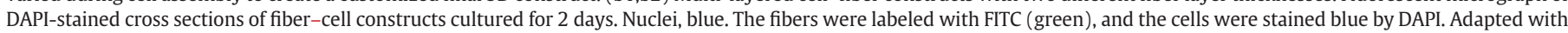
permission from [114] 2008 copyright Mary Ann Liebert. 
thickness. A similar approach aimed at producing a thicker nanofibrous network on a microfibrous structure using alternate processes of electrospinning and direct deposition of polymer melt [112]. Ultimately, those approaches attempted to combine the 3D scaffolding merit of a microfibrous support with a nanofibrous network. The cell responses were significantly enhanced when the electrospun nanofibrous network was present on the microfibrous scaffold. Modifying a collector part with conducting patterned polymers made it possible to pattern a nanofibrous network [113].

One recent report showed the engineering of 3D tissue constructs using a thin nanofibrous substrate [114]. A tissue-mimicking 3D construct was developed by the alternate stacking of cells and thin nanofiber substrate (Fig. 13). The idea was to culture the cells on the thin 2D nanofibrous substrate and then build 3D cell-nanofiber constructs using a layer-by-layer approach. As the cells can easily penetrate a thin layer of nanofibers, the method was proposed to mimic the native 3D tissue structure. Although suggested particularly effective for engineering layered tissues, such as skin, the approach can also be applied to the elaboration of 3D bone structure.

As described above, some technological advances are in progress to fully utilize the electrospun nanofibers in tissue engineering applications, including bone regenerative area. Given that the scaffolds for bone tissue engineering need to be qualified for specific mechanical properties as well as for biological compatibility, the 3D structural design of nanofibers and their scaffolding with tissue cells should be considered carefully in order to achieve properties analogous to the native bone ECM. Although few studies have been carried out using a nanofibrous matrix in bone tissue engineering, promising outcomes may be reported in the near future.

\section{Concluding remarks}

A significant amount of research has been directed to electrospinning nanofibrous materials targeted for bone regeneration. The selection of materials with the appropriate composition is of utmost importance in the successful generation of bone ECM mimicking matrices suitable for neo-bone formation. As described in this review, a range of degradable polymeric materials have demonstrated utility for bone regeneration. In particular, recent efforts have been focused on the incorporation of bioactive inorganic nanoparticles within the polymeric phase reaping up the combinatory roles of bone-bioactivity and rigidity of inorganic phase and degradability and shape-formability of polymers. Moreover, there is increasing research on the surface functionalization of nanofibers, such as mineralization of the polymeric surface and coupling with proteins/ peptides, to regulate cell functions from the initial cell adhesion to osteogenic stimulation of progenitor/stem cells. Materials that can elicit therapeutic effects by incorporating bio-signaling molecules within the nanofibers, such as antibiotics and proteins and genes pre-loaded in nanocapsules, hold great promise as scaffolds with drug delivery potential. To make full use of 3D cell culturing and tissue engineering, there has been considerable research aimed at developing macroporous morphology as well as shaping the nanofibrous structure by apparatus design and engineering cell-material constructs.

\section{Acknowledgements}

This work was supported by grants from the Korea Science and Engineering Foundation (KOSEF) funded by MOST (No. R01-2007000-20183-0) and the Korea Research Foundation funded by MOEHRD Basic Research Promotion Fund (No. KRF-2007-314-E00183).

\section{References}

[1] R. Langer, J.P. Vacanti, Tissue engineering, Science 260 (1993) 920-926.

[2] R.M. Nerem, A. Sambanis, Tissue engineering: from biology to biological substitute, Tissue Eng. 1 (1995) 3-13.
[3] K.J.L. Burg, S. Porter, J.F. Kellam, Biomaterial developments for bone tissue engineering, Biomaterials 21 (2000) 2347-2359.

[4] M.M. Stevens, Biomaterials for bone tissue engineering, Mater. Today 11 (2008) $18-25$.

[5] D.W. Hutmacher, Scaffolds in tissue engineering bone and cartilage, Biomaterials 21 (2000) 2529-2543.

[6] D. Liang, B.S. Hsiao, B. Chu, Functional electrospun nanofibrous scaffolds for biomedical applications, Adv. Drug Deliv. Rev. 59 (2007) 1392-1412.

[7] Q.P. Pham, U. Sharma, A.G. Mikos, Electrospinning of polymeric nanofibers for tissue engineering applications: a review, Tissue Eng. 12 (2006) 1197-1211.

[8] T.J. Sill, H.A. Recum, Electrospinning: applications in drug delivery and tissue engineering. Biomaterials 29 (2008) 1989-2006.

[9] C.P. Barnes, S.A. Sell, E.D. Boland, D.G. Simpson, G.L. Bowlin, Nanofiber technology: designing the next generation of tissue engineering scaffolds, Adv. Drug Deliv. Rev. 59 (2007) 1413-1433.

[10] Z. Ma, M. Kotaki, R. Inai, S. Ramakrishna, Potential of nanofiber matrix as tissueengineering scaffolds, Tissue Eng. 11 (2005) 101-109.

[11] H. Yoshimoto, Y.M. Shin, H. Terai, J.P. Vacanti, A biodegradable nanofiber scaffold by electrospinning and its potential for bone tissue engineering. Biomaterials 24 (2003) 2077-2082

[12] N. Ashammakhi, A. Ndreu, Y. Yang, H. Ylikauppila, L. Nikkola, V. Hasirci, Tissue engineering: a new take-off using nanofiber-based scaffolds, J. Craniofac. Surg. 18 (2007) 3-17.

[13] K.M. Woo, J.H. Jun, V.J. Chen, J.H. Seo, J.H. Baek, H.M. Ryoo, G.S. Kim, M.J. Somerman, P.X. Ma, Nano-fibrous scaffolding promotes osteoblast differentiation and biomineralization, Biomaterials 28 (2007) 335-343.

[14] I. Bab, B.A. Ashton, D. Gazit, G. Marx, M.C. Williamson, M.E. Owen, Kinetics and differentiation of marrow stromal cells in diffusion chambers in vivo, J. Cell Sci. 84 (1986) 139-151.

[15] T.M. Skerry, L. Bitensky, J. Chayen, L.E. Lanyon, Early strain-related changes in enzyme activity in osteocytes following bone loading in vivo, J. Bone Miner. Res. 4 (1989) 783-788

[16] G. Vaes, Cellular biology and biochemical mechanism of bone resorption. A review of recent developments on the formation, activation, and mode of action of osteoclasts, Clin. Orthop. Relat. Res. (1988) 239-271.

[17] R. Baron, Molecular mechanisms of bone resorption by the osteoclast, Anat. Rec. 224 (1989) 317-324.

[18] R. Baron, Polarity and membrane transport in osteoclasts, Connect. Tissue Res. 20 (1989) $109-120$

[19] S. Shi, M. Kirk, A.J. Kahn, The role of type I collagen in the regulation of the osteoblast phenotype, J. Bone Miner. Res. 11 (1996) 1139-1145.

[20] P.A. Price, A.A. Otsuka, J.W. Poser, J. Kristaponis, N. Raman, Characterization of a gamma-carboxyglutamic acid-containing protein from bone, Proc. Natl. Acad. Sci. U.S.A. 73 (1976) 1447-1451.

[21] M.D. McKee, M.J. Glimcher, A. Nanci, High-resolution immunolocalization of osteopontin and osteocalcin in bone and cartilage during endochondral ossification in the chicken tibia, Anat. Rec. 234 (1992) 479-492.

[22] Q.Q. Hoang, F. Sicheri, A.J. Howard, D.S. Yang, Bone recognition mechanism of porcine osteocalcin from crystal structure, Nature 425 (2003) 977-980.

[23] P.V. Hauschka, J.B. Lian, D.E. Cole, C.M. Gundberg, Osteocalcin and matrix Gla protein: vitamin K-dependent proteins in bone, Physiol. Rev. 69 (1989) 990-1047.

[24] P. Ducy, C. Desbois, B. Boyce, G. Pinero, B. Story, C. Dunstan, E. Smith, J. Bonadio, S. Goldstein, C. Gundberg, A. Bradley, G. Karsenty, Increased bone formation in osteocalcin-deficient mice, Nature 382 (1996) 448-452.

[25] W.T. Butler, The nature and significance of osteopontin, Connect. Tissue Res. 23 (1989) 123-136.

[26] D.T. Denhardt, X. Guo, Osteopontin: a protein with diverse functions, Faseb J. 7 (1993) 1475-1482

[27] H. Shiraga, W. Min, W.J. VanDusen, M.D. Clayman, D. Miner, C.H. Terrell, J.R. Sherbotie, J.W. Foreman, C. Przysiecki, E.G. Neilson, Inhibition of calcium oxalate crystal growth in vitro by uropontin: another member of the aspartic acidrich protein superfamily, Proc. Natl. Acad. Sci. U.S.A. 89 (1992) 426-430.

[28] J.W. Smith, D.J. Vestal, S.V. Irwin, T.A. Burke, D.A. Cheresh, Purification and functional characterization of integrin alpha $v$ beta 5 . An adhesion receptor for vitronectin, J. Biol. Chem. 265 (1990) 11008-11013.

[29] E.A. Wayner, N.L. Kovach, Activation-dependent recognition by hematopoietic cells of the LDV sequence in the V region of fibronectin, J. Cell Biol. 116 (1992) 489-497.

[30] C.A. Prater, J. Plotkin, D. Jaye, W.A. Frazier, The properdin-like type I repeats of human thrombospondin contain a cell attachment site, J. Cell Biol. 112 (1992) 1031-1040.

[31] F.G. Giancotti, E. Ruoslahti, Integrin signaling. Science 285 (1999) 1028-1032.

[32] J. Klein-Nulend, R.G. Bacabac, J.P. Veldhuijzen, J.J. Van Loon, Microgravity and bone cell mechanosensitivity, Adv. Space Res. 32 (2003) 1551-1559.

[33] D.E. Discher, P. Janmey, Y.L. Wang, Tissue cells feel and respond to the stiffness of their substrate, Science 310 (2005) 1139-1143.

[34] P.X. Ma, Biomimetic materials for tissue engineering, Adv. Drug Deliv. Rev. 60 (2008) 184-198.

[35] M.J. Olszta, X. Cheng, S.S. Jee, R. Kumar, Y.Y. Kim, M.J. Kaufman, E.P. Douglas, L.B. Gower, Bone structure and formation: a new perspective, Mater. Sci. Eng., R 58 (2007) 77-116.

[36] M.P. Lutolf, J.A. Hubbell, Synthetic biomaterials as instructive extracellular microenvironments for morphogenesis in tissue engineering, Nat. Biotechnol. 23 (2005) 47-55.

[37] C.I. Civin, L.C. Strauss, C. Brovall, M.J. Fackler, J.F. Schwartz, J.H. Shaper, Antigenic analysis of hematopoiesis. III. A hematopoietic progenitor cell surface antigen 
defined by a monoclonal antibody raised against KG-1a cells, J. Immunol, 133 (1984) 157-165

[38] S.E. Haynesworth, J. Goshima, V.M. Goldberg, A.I. Caplan, Characterization of cells with osteogenic potential from human marrow, Bone 13 (1992) 81-88.

[39] M.F. Pittenger, A.M. Mackay, S.C. Beck, R.K. Jaiswal, R. Douglas, J.D. Mosca, M.A. Moorman, D.W. Simonetti, S. Craig, D.R. Marshak, Multilineage potential of adult human mesenchymal stem cells, Science 284 (1999) 143-147.

[40] R.G. Young, D.L. Butler, W. Weber, A.I. Caplan, S.L. Gordon, D.J. Fink, Use of mesenchymal stem cells in a collagen matrix for Achilles tendon repair, J. Orthop. Res. 16 (1998) 406-413.

[41] N.J. Zvaifler, L. Marinova-Mutafchieva, G. Adams, C.J. Edwards, J. Moss, J.A. Burger R.N. Maini, Mesenchymal precursor cells in the blood of normal individuals, Arthritis Res. 2 (2000) 477-488.

[42] G.Z. Eghbali-Fatourechi, J. Lamsam, D. Fraser, D. Nagel, B.L. Riggs, S. Khosla, Circulating osteoblast-lineage cells in humans, N. Engl. J. Med. 352 (2005) 1959-1966.

[43] M.W. Long, J.L. Williams, K.G. Mann, Expression of human bone-related proteins in the hematopoietic microenvironment, J. Clin. Invest. 86 (1990) 1387-1395.

[44] S. Otsuru, K. Tamai, T. Yamazaki, H. Yoshikawa, Y. Kaneda, Bone marrow-derived osteoblast progenitor cells in circulating blood contribute to ectopic bone formation in mice, Biochem. Biophys. Res. Commun. 354 (2007) 453-458.

[45] K. Bieback, S. Kern, H. Kluter, H. Eichler, Critical parameters for the isolation of mesenchymal stem cells from umbilical cord blood, Stem Cells 22 (2004) 625-634.

[46] P.A. Zuk, Multilineage cells from human adipose tissue: implications for cellbased therapies, Tissue Eng. 7 (2001) 211-228.

[47] M.L. Brandi, P. Collin-Osdoby, Vascular biology and the skeleton, J. Bone Miner. Res. 21 (2006) 183-192.

[48] P. Madeddu, Therapeutic angiogenesis and vasculogenesis for tissue regeneration, Exp. Physiol. 90 (2005) 315-326.

[49] F. Geiger, B. Helge, B. Irina, L. Helga, W. Olga, E. Christina, S. Hans-Georg, R. Wiltrud, Vascular endothelial growth factor gene-activated matrix (VEGF165-GAM) enhances osteogenesis and angiogenesis in large segmental bone defects, J. Bone Miner. Res. 20 (2005) 2028-2035.

[50] Y.C. Huang, D. Kaigler, K.G. Rice, P.H. Krebsbach, D.J. Mooney, Combined angiogenic and osteogenic factor delivery enhances bone marrow stromal celldriven bone regeneration, J. Bone Miner. Res. 20 (2005) 848-857.

[51] M. Ehrbar, M.P. Lütolf, S.C. Rizzi, J.A. Hubbell, F.E. Weber, Artificial extracellular matrices for bone tissue engineering, Bone 42 (2008) S72.

52] R.Z. LeGeros, Properties of osteoconductive biomaterials: calcium phosphates, Clin. Orthop. Relat. Res. (2003) 81-98.

[53] A. Gigante, S. Manzotti, C. Bevilacqua, M. Orciani, R. Di Primio, M. Mattioli-Belmonte, Adult mesenchymal stem cells for bone and cartilage engineering: effect of scaffold materials, Eur. J. Histochem. 52 (2008) 169-174.

[54] M. Shin, H. Yoshimoto, J.P. Vacanti, In vivo bone tissue engineering using mesenchymal stem cells on a novel electrospun nanofibrous scaffold, Tissue Eng. 10 (2004) 33-41,

[55] A.S. Badami, M.R. Kreke, M.S. Thompson, J.S. Riffle, A.S. Goldstein, Effect of fiber diameter on spreading, proliferation, and differentiation of osteoblastic cells on electrospun poly(lactic acid) substrates, Biomaterials 27 (2006) 596-606.

[56] K. Sombatmankhong, N. Sanchavanakit, P. Pavasant, P. Supaphol, Bone scaffolds from electrospun fiber mats of poly(3-hydroxybutyrate), poly(3-hydroxybutyrate-co-3-hydroxyvalerate) and their blend, Polymer 48 (2007) 1419-1427.

[57] Y. Zhang, H. Ouyang, C.T. Lim, S. Ramakrishna, Z.M. Huang, Electrospinning of gelatin fibers and gelatin/PCL composite fibrous scaffolds, J. Biomed. Mater. Res. Part B: Appl. Biomater. 72 (2004) 156-165.

[58] H.W. Kim, H.S. Yu, H.H. Lee, Nanofibrous matrices of poly(lactic acid) and gelatin polymeric blends for the improvement of cellular responses, J. Biomed. Mater. Res., Part A 87A (2007) 25-32.

[59] E. Luong-Van, L. Grøndahl, S.J. Song, V. Nurcombe, S. Cool, The in vivo assessment of a novel scaffold containing heparan sulfate for tissue engineering with human mesenchymal stem cells, J. Mol. Hist. 38 (2007) 459-468.

[60] K. Ma, C.K. Chan, S. Liao, W.Y.K. Hwang, Q. Feng, S. Ramakrishna, Electrospun nanofiber scaffolds for rapid and rich capture of bone marrow-derived hematopoietic stem cells, Biomaterials 29 (2008) 2096-2103.

[61] Z. Ma, W. He, T. Yong, S. Ramakrishna, Grafting of gelatin on electrospun poly (caprolactone) nanofibers to improve endothelial cell spreading and proliferation and to control cell orientation, Tissue Eng. 11 (2005) 1149-1158.

[62] J.A. Matthews, G.E. Wnek, D.G. Simpson, G.L. Bowlin, Electrospinning of collagen nanofibers, Biomacromolecules 3 (2002) 232-238.

[63] Y.R.V. Shin, C.N. Chen, S.W. Tsai, Y.J. Wang, O.K. Lee, Growth of mesenchymal stem cells on electrospun type I collagen nanofibers, Stem Cells 24 (2006) 2391-2397.

[64] D.I. Zeugolis, S.T. Khew, E.S.Y. Yew, A.K. Ekaputra, Y.W. Tong, L.L. Yung D.W. Hutmacher, C. Sheppard, M. Raghunath, Electro-spinning of pure collagen nano-fibres - just an expensive way to make gelatin? Biomaterials 29 (2008) 2293-2305.

[65] H.J. Jin, J.S. Chen, V. Karageorgiou, G.H. Altman, D.L. Kaplan, Human bone marrow stromal cell responses on electrospun silk fibroin mats, Biomaterials 25 (2004) 1039-1047.

[66] C. Meechaisue, P. Wutticharoenmongkol, R. Waraput, T. Huangjing, N. Ketbumrung, P. Pavasant, P. Supaphol, Preparation of electrospun silk fibroin fiber mats as bone scaffolds: a preliminary study, Biomed. Mater. 2 (2007) 181-188.

[67] M. Li, H.J. Jin, G.D. Botsaris, D.L. Kaplan, Silk apatite composites from electrospun fibers, J. Mater. Res. 20 (2005) 3374-3384.

[68] K. Ohkawa, D. Cha, H. Kim, A. Nishida, H. Yamamoto, Macromol. Rapid Commun. 25 (2004) 1600-1605.

[69] S.Y. Shin, H.N. Park, K.H. Kim, M.H. Lee, Y.S. Choi, Y.J. Park, Y.M. Lee, I.C. Rhyu, S.B. Han, S.J. Lee, C.P. Chung, Biological evaluation of chitosan nanofiber membrane for guided bone regeneration, J. Periodontol. 76 (2005) 1778-1784.
[70] H.W. Kim, H.E. Kim, J.C. Knowles, Production and potential of bioactive glass nanofibers as a next-generation biomaterial, Adv. Funct. Mater. 16 (2006) 1529-1535

[71] H.W. Kim, H.E. Kim, Nanofiber generation of hydroxyapatite and fluorhydroxyapatite bioceramics, J. Biomed. Mater. Res., Part B: Appl. Biomater. 22B (2005) 323-328.

[72] Y. Wu, L.L. Hench, J. Du, K.L. Choy, J. Guo, Preparation of hydroxyapatite fibers by electrospinning technique, J. Am. Ceram. Soc. 87 (2004) 1988-1991.

[73] X. Dai, S. Shivkumar, Electrospinning of PVA-calcium phosphate sol precursors for the production of fibrous hydroxyapatite, J. Am. Ceram. Soc. 90 (2007) 1412-1419,

[74] S. Sakai, Y. Yamada, T. Yamaguchi, K. Kawakami, Prospective use of electrospun ultra-fine silicate fibers for bone tissue engineering Biotechnol.J. 1 (2006) 958-962.

[75] H.W. Kim, H.H. Lee, J.C. Knowles, Nanofibrous glass tailored with apatitefibronectin interface for bone cell stimulation, J. Nanosci. Nanotechnol. 8 (2008) 3013-3019.

[76] H.W. Kim, J.H. Song, H.E. Kim, Bioactive glass nanofiber-collagen nanocomposite as a novel bone regeneration matrix, J. Biomed. Mater. Res., Part A 79A (2006) 698-705.

77] H.W. Kim, H.H. Lee, G.S. Chun, Bioactivity and osteoblast responses of nove biomedical nanocomposites of bioactive glass nanofiber filled poly(lactic acid), J. Biomed. Mater. Res., Part A 85A (2008) 651-663.

[78] K. Rezwan, Q.Z. Chen, J.J. Blaker, A.R. Boccaccini, Biodegradable and bioactive porous polymer/inorganic composite scaffolds for bone tissue engineering Biomaterials 27 (2006) 3413-3431.

[79] H.W. Kim, J.H. Song, H.E. Kim, Nanofiber generation of gelatin-hydroxyapatite biomimetics for guided tissue regeneration, Adv. Funct. Mater. 15 (2005) 1988-1994.

[80] J.H. Song, H.E. Kim, H.W. Kim, Electrospun fibrous web of collagen-apatite precipitated nanocomposite for bone regeneration, J. Mater. Sci., Mater. Med. 19 (2008) 2925-2932.

[81] Y. Zhang, J.R. Venugopal, A. El-Turki, S. Ramakrishna, B. Su, C.T. Lim, Electrospun biomimetic nanocomposite nanofibers of hydroxyapatite/chitosan for bone tissue engineering, Biomaterials 29 (2008) 4314-4322.

[82] K. Fujihara, M. Kotaki, S. Ramakrishna, Guided bone regeneration membrane made of polycaprolactone/calcium carbonate composite nano-fibers, Biomaterials 26 (2005) 4139-4147.

[83] H.W. Kim, H.H. Lee, J.C. Knowles, Electrospinning biomedical nanocomposite fibers of hydroxyapaite/poly (lactic acid) for bone regeneration, J. Biomed. Mater. Res., Part A 79 (2006) 643-649.

[84] J.H. Song, B.H. Yoon, H.E. Kim, H.W. Kim, Bioactive and degradable hybridized nanofibers of gelatin-siloxane for bone regeneration, J. Biomed. Mater. Res., Part A 84A (2007) 875-884.

[85] J. Venugopal, P. Vadgama, T.S. SampathKumar, S. Ramakrishna, Biocomposite nanofibres and osteoblasts for bone tissue engineering, Nanotechnology 18 (2007) $1-8$

[86] C. Erisken, D.M. Kalyon, H. Wang, Functionally graded electrospun polycaprolactone and $\beta$-tricalcium phosphate nanocomposites for tissue engineering applications, Biomaterials 29 (2008) 4065-4073.

[87] H.S. Yu, J.H. Jang, T.I. Kim, H.H. Lee, H.W. Kim, Apatite-mineralized polycaprolactone nanofibrous web as a bone tissue regeneration substrate, J. Biomed. Mater. Res., Part A 88 (2009) 747-754.

[88] S.H. Park, T.I. Kim, Y. Ku, C.P. Ching, S.B. Han, J.H. Yu, S.P. Lee, H.W. Kim, H.H. Lee, Effect of hydroxyapatite-coated nanofibrous membrane on the responses of human periodontal ligament fibroblast, J. Ceram. Soc. Jpn. 116 (2008) 31-35.

[89] J. Chen, B. Chu, B.S. Hsiao, Mineralization of hydroxyapatite in electrospun nanofibrous poly(L-lactic acid) scaffolds, J. Biomed. Mater. Res., Part A 79 (2006) $307-317$.

[90] W. Cui, X. Li, S. Zhou, J. Weng, In situ growth of hydroxyapatite with electrospun poly(DL-lactide) fibers, J. Biomed. Mater. Res., Part A 82A (2007) 831-841.

[91] M. Ngiam, S. Liao, A.J. Patil, Z. Cheng, F. Yang, M.J. Gubler, S. Ramakrishna, C.K. Chan, Fabrication of mineralized polymeric nanofibrous composites for bone graft materials, Tissue Eng.: Part A 14 (2008) 1-12.

[92] Q.Q. Hoang, F. Sicheri, A.J. Howard, D.S. Yang, Bone recognition mechanism of porcine osteocalcin from crystal structure, Nature 425 (2003) 977-980.

[93] D. Wang, S.C. Miller, P. Kopečková, J. Kopeček, Bone-targeting macromolecular therapeutics, Adv. Drug Deliv. Rev. 57 (2005) 1049-1076.

[94] T.G. Kim, T.G. Park, Biomimicking extracellular matrix: cell adhesive RGD peptide modified electrospun poly(D,L-lactic-co-glycolic acid) nanofiber mesh, Tissue Eng. 12 (2006) 221-233.

[95] J.F. Alvarez-barreto, M.C. Shreve, P.L. Deanqelis, V.I. Sikavitsas, Preparation of a functionally flexible, three-dimensional, biomimetic poly(L-lactic acid) scaffold with improved cell adhesion, Tissue Eng. 13 (2007) 1205-1217.

[96] G. Buschle-Diller, J. Cooper, Z. Xie, Y. Wu, J. Waldrup, X. Ren, Release of antibiotics from electrospun bicomponent fibers, Cellulose 14 (2007) 553-562.

[97] K.S. Kim, Y.K. Luu, C. Chang, D. Fang, B.S. Hsiao, B. Chu, M. Hadjiargyrou, Incorporation and controlled release of a hydrophilic antibiotic using poly(lactide-co-glycolide)based electrospun nanofibrous scaffolds, J. Control. Release 98 (2004) 47-56.

[98] C. Li, C. Vepari, H.J. Jin, H.J. Kim, D.L. Kaplan, Electrospun silk-BMP-2 scaffolds for bone tissue engineering, Biomaterials 27 (2006) 3115-3124.

[99] Y.K. Luu, K. Kim, B.S. Hsiao, B. Chu, M. Hadjiargyrou, Development of nanostructured DNA delivery scaffold via electrospinning of PLGA and PLA-PEC block copolymers, J. Control. Release 89 (2003) 341-353.

100] B. Chu, D. Liang, M. Hadjiargyrou, B.S. Hsiao, A new pathway for developing in vitro nanostructured non-viral gene carriers, J. Phys., Condens. Matter 18 (2006) S2513-S2525.

[101] H. Nie, C.H. Wang, Fabrication and characterization of PLGA/HAp composite scaffolds for delivery of BMP-2 plasmid DNA, J. Control. Release 120 (2007) $111-121$. 
[102] M. Hadjiargyrou, J.B. Chiu, Enhanced composite electrospun nanofiber scaffolds for use in drug delivery, Exp. Opin. Drug Deliv. 5 (2008) 1093-1106.

103] Z.C. Sun, E. Zussman, A.L. Yarin, J.H. Wendorff, A. Greiner, Compound core-shel polymer nanofibers by co-electrospinning, Adv. Mater. 15 (2003) 1929.

104] H. Jiang, Y. Hu, P. Zhao, Y. Li, K. Zhu, Modulation of protein release from biodegradable core-shell structured fibers prepared by coaxial electrospinning, J. Biomed. Mater. Res., Part B: Appl. Biomater. 79B (2006) 50-57.

[105] D. Zhang, J. Chang, Electrospinning of three-dimensional nanofibrous tubes with controllable architectures, Nano Lett. 8 (2008) 3283-3287.

106] J. Rouwkema, N.C. Rivron, C.A. van Blitterswijk, Vascularization in tissue engineering, Trends Biotechnol. 26 (2008) 434-441.

107] D. Hutmacher, T. Woodfield, P. Dalton, J. Lewis, Scaffold design and fabrication, Tissue Eng. (2008) 403-454.

[108] J.J. Lee, H.S. Yu, S.J. Hong, I. Jeong, J.H. Jang, H.W. Kim, Nanofibrous membrane of collagen-polycaprolactone for cell growth and tissue regeneration, J. Mater. Sci. Mater. Med. (2009), doi:10.1007/s10856-009-3743-z.
[109] J. Nam, Y. Huang, S. Agarwal, J. Lannutti, Improved cellular infiltration in electrospun fiber via engineered porosity, Tissue Eng. 13 (2007) 2249-2257.

[110] Y.H. Lee, J.H. Lee, I.-G. An, C. Kim, D.S. Lee, Y.K. Lee, J.-D. Nam, Electrospun dualporosity structure and biodegradation morphology of montmorillonite reinforced PLLA nanocomposite scaffolds, Biomaterials 26 (2005) 3165-3172.

[111] K. Tuzlakoglu, N. Bolgen, A.J. Salgado, M.E. Gomes, E. Piskin, R.L. Reis, Nano- and micro-fiber combined scaffolds: a new architecture for bone tissue engineering, J. Mater. Sci., Mater. Med. 16 (2005) 1099-1104.

[112] S.H. Park, T.G. Kim, H.C. Kim, D.Y. Yang, T.G. Park, Development of dual scale scaffolds via direct polymer melt deposition and electrospinning for applications in tissue regeneration, Acta Biomater. 4 (2008) 1198-1207.

[113] D. Zhang, J. Chang, Patterning of electrospun fibers using electroconductive templates, Adv. Mater. 19 (2007) 3664-3667.

[114] X. Yang, J.D. Shah, H. Wang, Nanofiber enabled layer-by-layer approach toward three-dimensional tissue formation, Tissue Eng.: Part A 14 (2008) 1-12.
1154 1155 1156

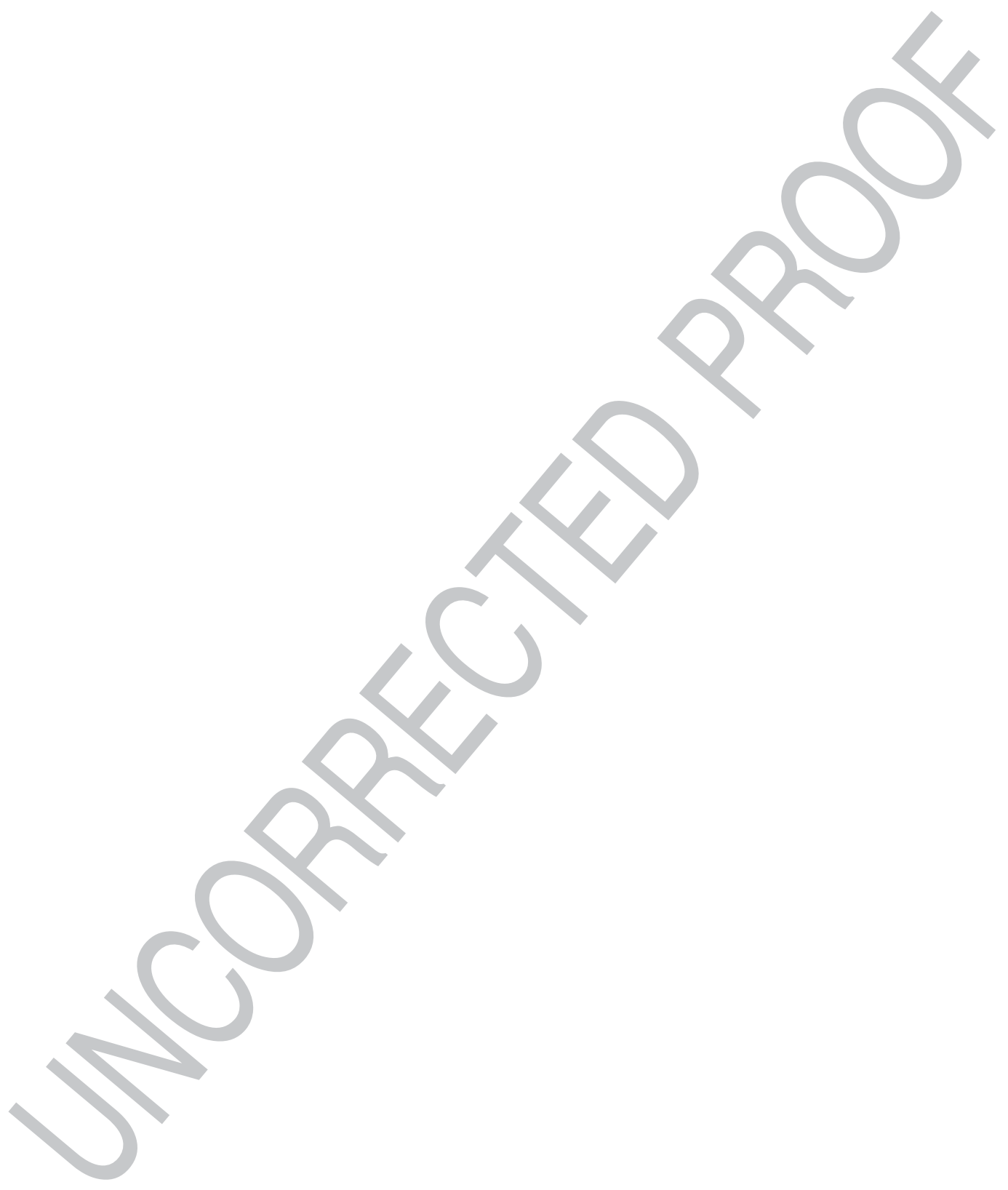

